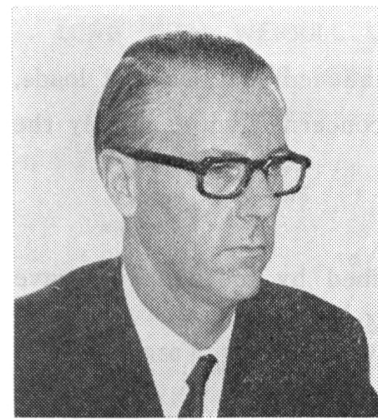

\title{
Some Developments in the Area of Strength and Vibration of Ships
}

\author{
Egil Abrahamsen*
}

(Paper presented at a special lecture meeting of The Society of Naval Archtects of Japan in Tokyo on 18 April 1972)

\section{Abstract}

This paper describes primarily progress during the last two years in the areas of wave induced motions and loads, finite element technique, and propeller induced loads and propeller design. Various examples are given to reflect applications to hull as well as machinery structures.

\section{Introduction}

In areas related to the prediction of wave induced motions and loads, and the structural analysis of very complex configurations, the marine profession has reached a very advanced level in the recent years. Currently the emphasis is being put on the joining of these areas through e.g. integrated dynamic simulation. On such a basis it is to be expected that the probabilistic design approach will have a break through of practical significance. It is thus likely that the shipbuilding profession soon will employ a fully developed probabilistic design scheme as an alternative to existing rule texts.

Practical methods for the design of propulsors and evaluation of associated hydrodynamic phenomena have progressed rapidly in the recent years. Both model- and full-scale verifications are available to substantiate the theory. Those responsible for afterbody design of high-powered ships will particularly appreciate the tools available for initial design scrutinization.

The interaction of hull and machinery structures has long been subject to uncertainty, and has-in view of lack of practical predictive means-been treated somewhat cursory on the basis of previous experience and overly crude predictors. The consequences of forecasting integral behaviour on this basis have been rather unfortunate in many instances.

This paper endeavours to review some of the advances which have been made in the above mentioned areas. It also discusses in which directions further research efforts are pointed.

\section{Wave Induced Motions and Loads}

\section{Theoretical development}

The rapid increase in ship size that took place in the fifties and sixties showed beyond doubt that it was no longer sufficient to rely on experience from the smaller ships when evaluating strength criteria for the large ships. It was obvious that more effort would have to be put into solving the problem of the wave induced loads. Det norske Veritas took the consequence of this situation and in the early sixties started a group

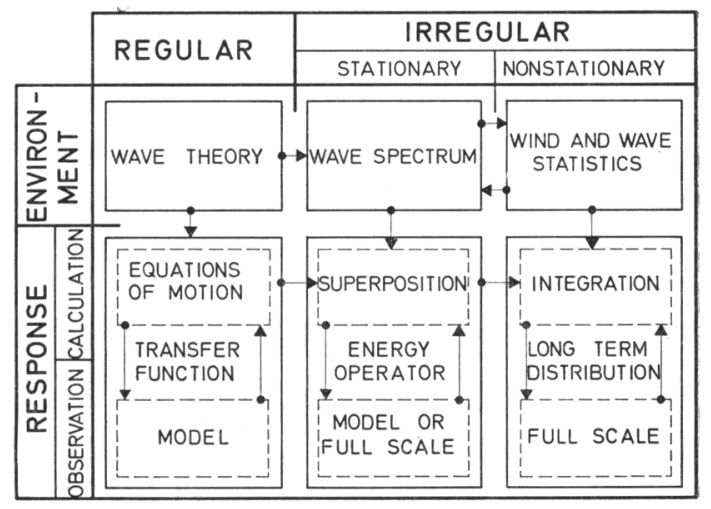

Fig. 1

\footnotetext{
* Managing Director, Det norske Veritas
} 
for wave load investigations.

Figure 1 gives a broad picture of the scheme used for predicting wave induced motions and loads, and it also illustrates one of the first tasks that this group had to be concerned with, namely the description of the environment.

\section{Description of the waves}

The short term state of sea (stationary wave conditions) may be described by means of a wave spectrum. We have used the type of spectrum proposed by Pierson and Moskowitz ${ }^{1} *$

where

$$
|a(\omega)|^{2}=A \omega^{-5} \exp \left(-B \omega^{-4}\right)
$$

$$
\omega \text {-wave frequency; } A, B \text {-constants. }
$$

$A$ and $B$ are given in terms of significant wave height, $H_{1 / 3}$, and average apparent wave period, $\bar{T} . H_{1 / 3}$ is related to the total energy content of the wave system, and $\bar{T}$ locates the spectrum along the frequency axis.

Once $H_{1 / 3}$ is known the statistical distribution of individual wave heights is given by the Rayleigh distribution

$$
P(H)=1-\exp \left(-2\left(H / H_{1 / 3}\right)^{2}\right)
$$

where $P(H)$ is the probability that the wave height is smaller than or equal to $H$. By wave height is here meant the vertical distance between crest and trough.

As is understood from the above we need information on $H_{1 / 3}$ and $\bar{T}$ in order to be able to describe the sea. There is, however, a drawback with most of the available data, namely that they are visual estimates. Although definite rules are given as to the way waves should be observed, it is obvious that visual observations cannot be as accurate as instrumental recordings. In order to be able to utilize the large amount of visual wave observations Nordenstr $\phi \mathrm{m}^{2}$ ) has analyzed simultaneous recordings and visual estimates and arrived at transformation formulae of the following type

$$
\begin{aligned}
& H_{1 / 3}=A_{H} H_{V}^{B H} \\
& \bar{T}=A_{T} T_{V}^{B T}
\end{aligned}
$$

where the subscripts $V, H$ and $T$ denote visual observations, wave height and wave period, respectively.

Wave statistics from for instance the weatherships in the North Atlantic are given as the percentage of observations lying in a given period and wave height interval. An example based on data given by Walden ${ }^{3)}$ is shown in Fig. 2. It is seen that about 12 percent of all the observations had a wave

\begin{tabular}{|c|c|c|c|c|c|c|}
\hline \multirow{3}{*}{\multicolumn{2}{|c|}{$\begin{array}{l}\text { LONG TERM } \\
\text { PERCENT } \\
\text { WITHIN CLASS }\end{array}$}} & \multicolumn{5}{|c|}{ DATA } \\
\hline & & \multicolumn{5}{|c|}{ WAVE PERIOD } \\
\hline & & $<5$ & $5-7$ & $7-9$ & $\bullet \bullet$ & $\begin{array}{l}\text { ALL } \\
\text { PERIODS }\end{array}$ \\
\hline \multirow{5}{*}{$\begin{array}{l}\text { WAVE } \\
\text { HEIGHT }\end{array}$} & $0-0.75$ & 2.09 & 1.18 & 0.46 & $\bullet \bullet \bullet$ & 4.06 \\
\hline & $0.75-1.75$ & 7.28 & 13.10 & 6.30 & $\bullet \bullet \bullet$ & 28.77 \\
\hline & $1.75-2.75$ & 2.13 & 12.66 & 11.83 & $\bullet \bullet$ & 30.12 \\
\hline & $:$ & $:$ & $:$ & $:$ & - : • & $:$ \\
\hline & \begin{tabular}{|l|} 
ALL \\
HEIGHTS
\end{tabular} & 11.90 & 34.55 & 35.86 & $\bullet \bullet$ & 100 \\
\hline
\end{tabular}
height between $1.75 \mathrm{~m}$ and $2.75 \mathrm{~m}$ and at the same time a period between 7 and $9 \mathrm{sec}$.

The data given in Fig. 2 describes the long term behaviour of the sea. Nordenstr $\phi \mathrm{m}^{4)}$ found that Weibull distribution would be feasible for a mathematical representation of these data. An example based on Fig. 2 is shown in Fig. 3. The Weibull distribution is given as

Fig. 2

$$
P\left(H_{V}\right)=1-\exp \left(-\left(H_{V} / H_{C}\right)^{r}\right)
$$

where

$H_{C}, \gamma$-parameters of the distribution.

Now the relation between the visual estimate $H_{V}$ and the significant wave height $H_{1 / 3}$ is given by Eq. 3. Utilizing this relation the long term distribution of the short term parameter is found by Eq. 4. By combining this equation with the Rayleigh distribution of individual wave heights, Eq. 2, the long term distribution of individual wave heights may be found.

* Numbers inside parentheses denote References given in List of References. 
LONG TERM WEIBULL DISTRIBUTION OF WAVE HEIGHT

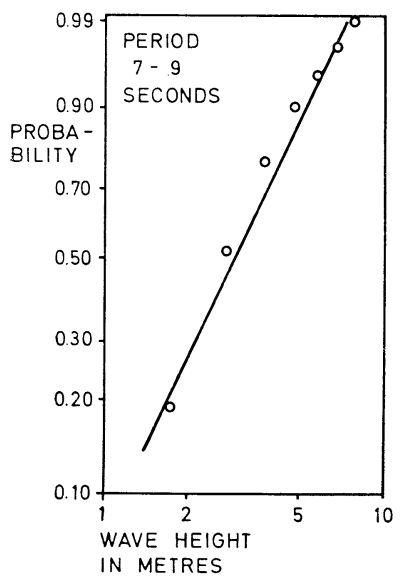

Fig. 3

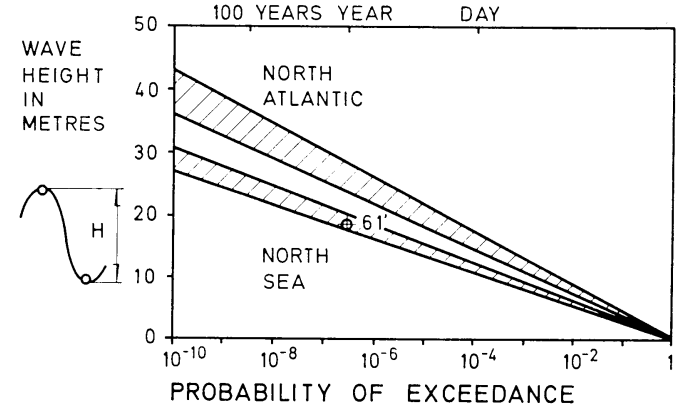

Fig. 4

This is again found to be well described by a Weibull distribution. As an example Fig. 4 has been prepared. The curves for the North Sea are based on data from the weather and rescue ship "Famita", while data according to Walden ${ }^{3)}$ is the basis for the North Atlantic curve.

From measurements on board "Famita" Draper"5) found a largest wave height of $61 \mathrm{ft}$. He considered this value as being representative of a typical winter, and it is seen that this corresponds well with our predictions.

\section{Response in regular waves}

An irregular wave system may be thought of as the sum of an infinite number of regular waves with random phase angles. As this super-position principle can be utilized also for ship motions and loads, a transfer function is a useful concept even if it does not represent realistic conditions that a ship will meet.

A transfer function gives the response of the ship to a sinusoidal wave of unit height. A transfer function may be determined by model tests or theoretical calculations. The last method is by far the fastest and cheapest, but the results will of course have to be checked against test results. In fact we have put much emphasis on the control of each step in our theoretical calculations against model tests and full scale calculations. See Fig. 1.

The vast amount of calculations necessary to obtain a transfer function would not be possible without the use of a computer. We have therefore put much effort in developing computer programmes suitable for our needs. Fig. 5 gives a survey of our wave load prediction programmes.

Our calculations of transfer functions have been based on the strip theory, assuming that the ship is divided into a number of transverse strips and considering the flow around each strip to be twodimensional. Our first programme in the field, NV 410, was based on the strip theory developed by Korvin-Kroukovsky and Jacobs's). This programme can only give vertical motions and the associated loads. Coefficients for added mass and damping have been calculated according to $\mathrm{Grim}^{\text {?) }}$. The original programme has been extended to include oblique headings according to a method

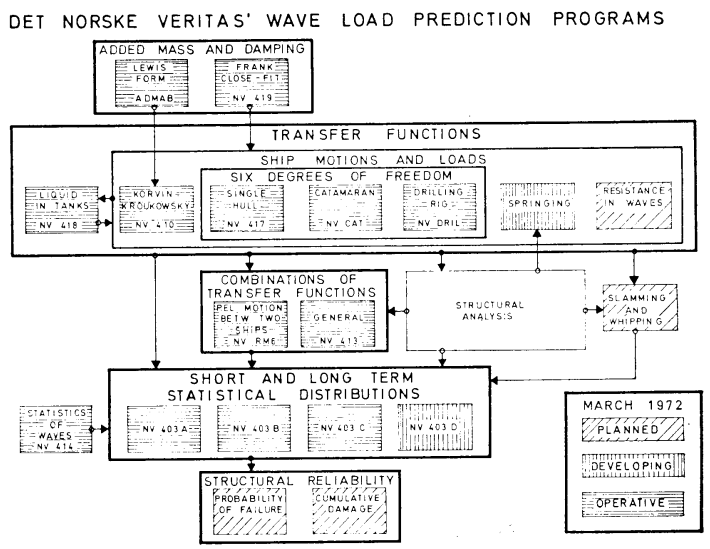

Fig. 5 
given by Fukudas).

In this programme the form of the ship is described by a so-called Lewis form. This description is feasible for most conventional ship forms, and the results obtained have been of great value. However, it is apparent that there is a need for a more accurate description of the ship form, and also for knowledge of ship motions and loads in all six degrees of freedom.

Both these requirements have been taken into account in our new computer programme, NV 417 . This programme is based on a theory as presented by Salvesen, Tuck and Faltinsen ${ }^{9)}$.

Here the ship form is given by a close-fit representation, i.e. each strip is described by giving a

ADDED MASS AND DAMPING COEFFICIENTS BY MEANS OF FRANK CLOSE FIT TECHNIQUE

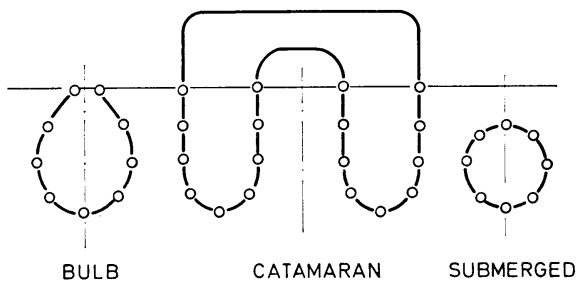

Fig. 6 number of coordinates for the cross-sectional contour. Practically any sectional form may be described in this way as illustrated in Fig. 6.

A sink-sourse theory is the basis for calculation. of added mass and damping coefficients, not only for the vertical motions heave and pitch, but alsc for sway, yaw, roll and surge. With this programme we are consequently able to calculate transfer functions for motions in all six degrees of freedom by solving a set of six coupled linear

differential equations. Also the associated loads, i.e. horizontal and vertical shear force, horizontal and vertical bending moment and torsional moment, are found by summation of the forces and moments for all strips.

As indicated in Fig. 6 catamaran sections may also be described by the close fit technique. It was a natural step to develop a computer programme for catamarans based on this same method. The

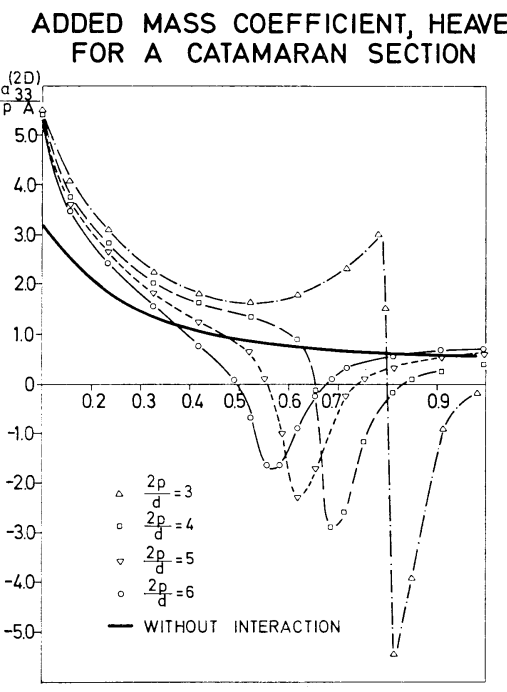

Fig. 7 method has been described in more detail by Nordenstrọm, Faltinsen and Pedersen ${ }^{10)}$. There is, however, one effect which is particular for a catamaran, namely the interaction between the two hulls. That this effect is of importance is illustrated in Fig. 7 which shows the added mass for heave motion calculated with and without interaction taken into account. Presently only motions and loads for a catamaran with zero forward speed can be calculated by the programme described above.

\section{Response in irregular waves}

The determination of transfer functions is the first step in the prediction of motions and loads in a seaway. As already mentioned this prediction is based on the superposition principle, i.e. that an infinite sum of regular response will give the irregular response experienced at sea. The superposition principle is generally accepted to be applicable to all motions and loads except may be rolling.

The wave spectrum describes an irregular sea state and by combining this with a transfer function a response spectrum is obtained.

The wave spectrum has only two parameters, $H_{1 / 3}$ and $\bar{T}$, and the ship response may thus be obtained as a function of the two same parameters. Analogously to $H_{1 / 3}$ for waves we define a parameter $E$ for the response. This is related to the area of the response spectrum, $m_{0}$, by 


$$
E=2 m_{0} \text {. }
$$

Also the amplitudes of the irregular response follow the Rayleigh distribution and $E$ is the only parameter,

$$
P(x)=1-\exp \left(-x^{2} / E\right) .
$$

As explained previously the long term distribution of wave conditions may be found from the statistics of $H_{1 / 3}$ and $\bar{T}$. Since $E$ is now given as a function of these two parameters the long term distribution of the response may be found. The long term response may in principle be found by summing an infinite number of short term responses as shown in Fig. 8.

An example of the long term distribution of vertical bending moment has been shown in Fig. 9 .

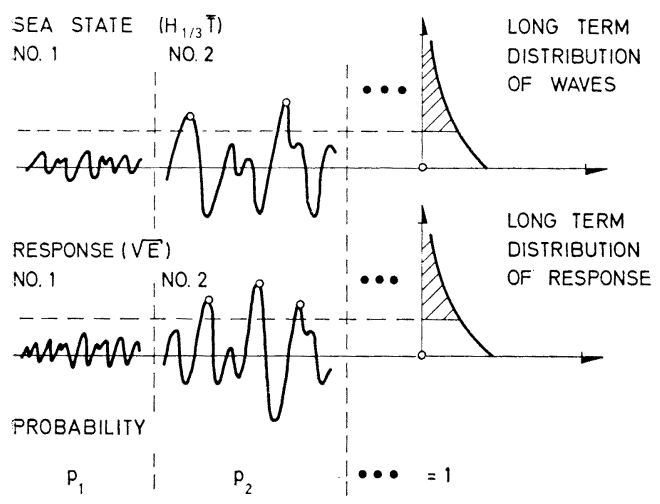

Fig. 8

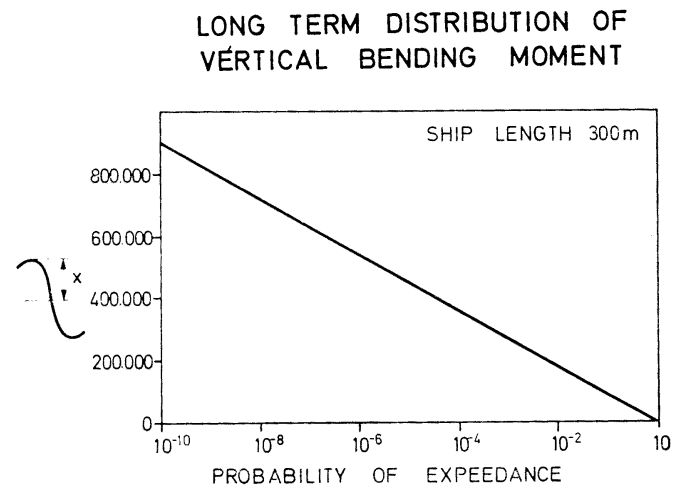

Fig. 9

This calculation has been based on wave statistics for the North Atlantic. The probability of exceedance, $10^{-8}$, corresponds to the most probable largest in $10^{8}$ response cycles which is practically equivalent to 20 years of operation of a ship or one average ship life. Fig. 10 shows how the vertical bending moment varies with ship size.

By applying the above procedure the long term distribution for each individual load may be found. However, such a procedure will not yield informa-

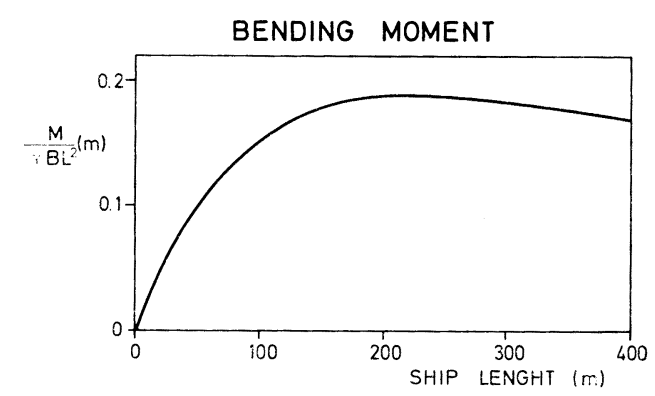

Fig. 10 tion concerned with the simultaneity of the responses. There is a very small probability that the value of, e.g., vertical bending corresponding to a probability level $10^{-8}$ should occur simultaneously with the value of, e.g., horizontal bending corresponding to a similarly low probability level.

Another way of utilizing the superposition principle, while keeping the correct phase angles, is by simulating the time history of the response. By reversing the procedure one may from a given directional wave spectrum find a number of regular waves which summed with random phase angles gives a time picture of an irregular sea state. Then the transfer function gives the response corresponding to each of the regular waves and the sum simulates the irregular response. As also the phase angles between the response and the wave are taken into account a realistic time history is simulated for the responses, both with respect to magnitude and simultaneity. An example of such a time history is shown in Fig. 11.

\section{Internal loads from liquid in tanks}

Internal loads may be divided in three categories: 
1) Stationary pressure forces acting on the tank wall or members of the internal structure.

2) Transient (slamming and other dynamic type) pressures.

3) Total loads on the tanks (moment and forces) resulting from integration of the static and dynamic

\section{SIMULATION OF SHIP MOTION}

$L=300 \mathrm{~m} \quad H_{1 / 3}=15 \mathrm{~m} \quad \bar{T}=10 \mathrm{sec}$

$V=19.5 \mathrm{knop}$

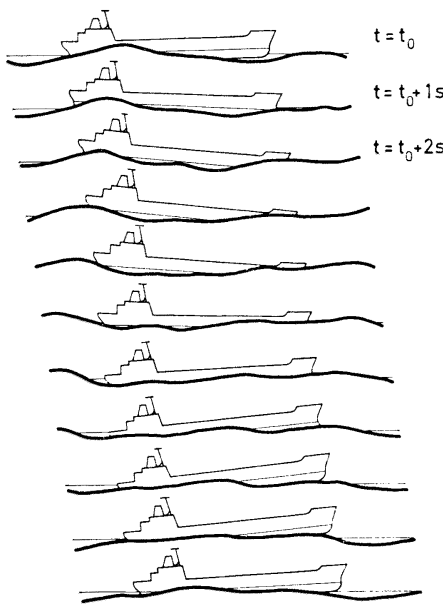

Fig. 11

masses mentioned in 1 and 2 .

In the case of full tanks the total loads and the stationary pressures are generally the important ones.

Such loads are predicted relatively simply on the basis of known ship motions and accelerations, neglecting the free surface effects in the tank.

In partly filled tanks all three types of internal loads may be significant, but a correct determination of their magnitudes is far more complicated. These loads are all connected to the free motion of liquid in the tank, caused by the oscillatory movements of the ship.

The response of the liquid to a forced motion depends on -the time variation of this exciting motion

-the geometry of the tank

-the amount of liquid in the tank

- the size of the tank

-the physical properties of the liquid in the tank.

Considering a tank of given shape and degree of filling, the latter four effects can in many cases be accounted for by employing appropriate laws of dynamic similitude. The time variation of the exciting motion is described by response spectra of ship motion.

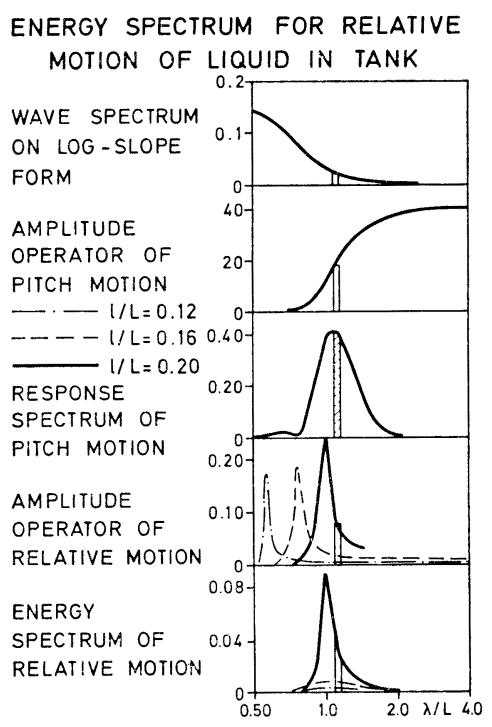

Fig. 12

Transfer functions for liquid responses are shown in Fig. 12. These kind of functions, which may be found theoretically or by experiments, are typical of liquid motions, stationary pressures and total loads. The shape of the curve will be essentially the same for different modes of excitation.

Assuming liquid responses proportional to the exciting motions, response spectra for liquid responses may be found by combining the response spectra of ship motion and the just mentioned transfer function. Analogously to the treatment of ship motions and loads in the previous section, the response spectra for internal loads may be used to predict long term distributions of these variables.

The liquid responses considered above are in general more or less nonlinear. However, the procedure outlined will in many cases yield acceptable solutions. In some cases it is also possible to modify such solutions, in order to allow somewhat for nonlinear effects.

The magnitude of transient pressures, which occur by impact between the sloshing liquid and a structural member, depends mainly on the impact velocity and the stiffness of the structure. The impact velocity may in principle be found in the same manner as the liquid motion, and the statistical treatment applied in slamming calculations may be adopted for the evaluation of long term pressure responses. 


\section{Experimental checks}

We consider it very important to check our theoretical results against experience both from model tests and full-scale measurements. We will here give a couple of examples which should clearly illustrate why we have reasonable confidence in our theoretical procedure.

Usually the best fit between theoretical and experimental results is obtained for vertical ship motions and loads. Fig. 13 shows a comparison between model test results and theoretical calculations with NV 410 for vertical bending moment in head seas. The model test results are according to

CALCULATED TRANSFER FUNCTIONS FOR S-6O COMPARED TO MODEL TESTS

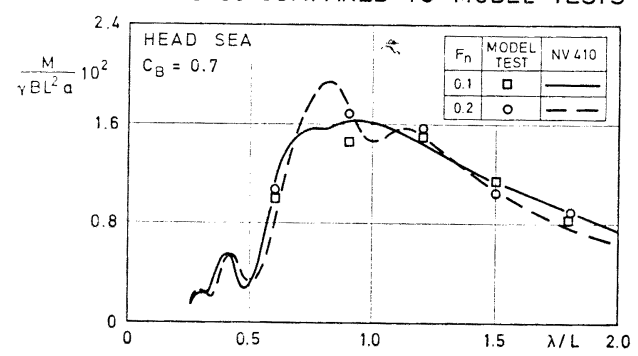

Fig. 13

Vossers et al.11) Just as good correlation was obtained by comparisons with full-scale measurements, as shown in Fig. 14.

We have also compared theoretical figures for transverse loads with the results presented by Wahab12). Two examples are shown in Figs. 15 and 16. More extensive comparisons are presented by Faltinsen ${ }^{13)}$.

As illustrated in Fig. 17 the correlation is reasonable also for catamarans.

The above examples can only serve as indications that the theoretical methods now available provide powerful tools for establishing the design loads for ships and shiplike configurations.

\section{Combined load-stress analysis}

We have in the foregoing sections briefly described

TORSIONAL MOMENT AMIDSHIPS

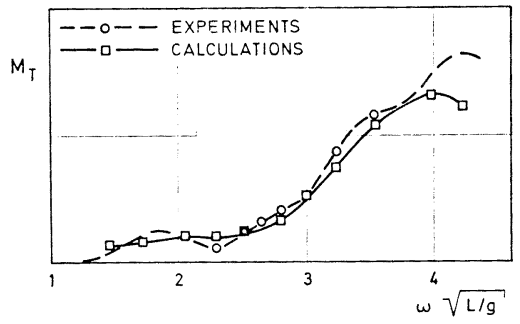

Fig. 16
PARAMETER OF MIDSHIP BENDING STRESSES

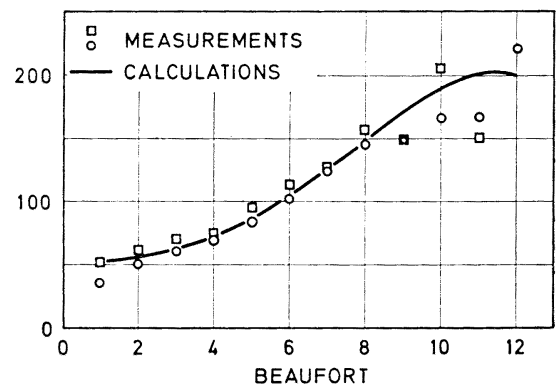

Fig. 14

HORIZONTAL BENDING MOMENT AMIDSHIPS

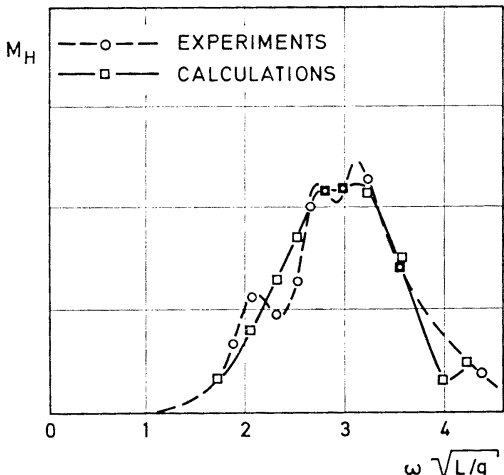

Fig. 15

HEAVE MOTION FOR CATAMARAN

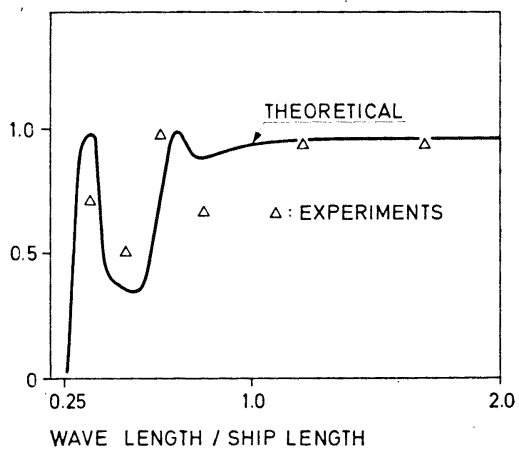

Fig. 17 
the methods and tools available for determining the loads. However, the application of statistical

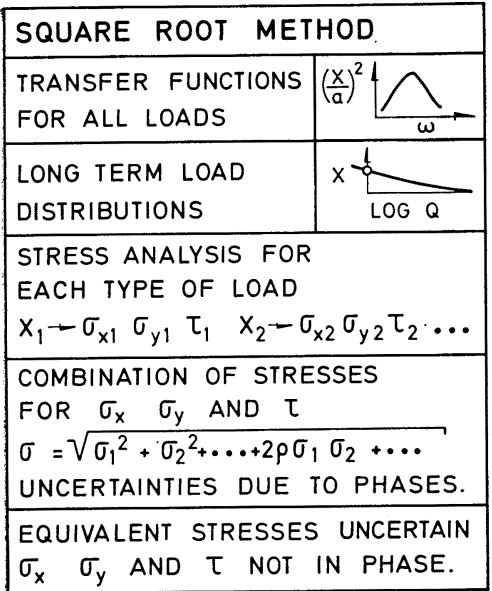

Fig. 18

\begin{tabular}{|l|l|}
\hline \multicolumn{2}{|l|}{ LONG TERM STRESS } \\
DISTRIBUTION. \\
\hline $\begin{array}{l}\text { TRANSFER FUNCTIONS } \\
\text { FOR ALL LOADS. }\end{array}$ \\
\hline STRESS ANALYSIS FOR \\
ALL FREQUENCIES GIVE \\
TRANSFER FUNCTIONS \\
FOR STRESSES. \\
FONG
\end{tabular}

Fig. 19

\begin{tabular}{|c|c|}
\hline $\begin{array}{l}\text { DYNAMIC EQUILIBRI } \\
\text { IN REGULAR WAVE. }\end{array}$ & \\
\hline $\begin{array}{l}\text { TRANSFER FUNCTIONS } \\
\text { FOR ALL LOADS. }\end{array}$ & \\
\hline $\begin{array}{l}\text { LONG TERM DISTRI - } \\
\text { BUTION FOR MOST } \\
\text { IMPORTANT LOAD. }\end{array}$ & LOGQ \\
\hline $\begin{array}{l}\text { EQUIVALENT REGULAR } \\
\text { WAVE GIVES REGULAR } \\
\text { STRESSES FROM ALL } \\
\text { LOADS. CORRECT PHASE }\end{array}$ & \\
\hline $\begin{array}{l}\text { EQUIVALENT STRESSES } \\
\sigma_{e}=\sqrt{\sigma_{x}^{2}+\sigma_{y}^{2}-\sigma_{x} \sigma_{y}+3}\end{array}$ & \\
\hline
\end{tabular}

Fig. 20 loads in connection with a strength analysis is not a straight forward procedure.

When trying to apply the calculated wave loads on a structure, the designer is faced with the problem of simultaneity. For example the vertical bending moment on the probability level $10^{-8}$ does not occur simultaneously with the horizontal bending moment at the same probability level. Consequently, a stress which is dependent of both moments cannot be obtained by a simple algebraic summation, but rather by vectorial summation.

This example illustrates the problem in a nutshell, and in order to be able to use the statistical loads in strength analysis, practical solutions will have to be found. We strongly emphasize the term "practical solution" and will here give some comments on four different methods that we now try to develop further.

The first method is termed the "square root method". As shown in Fig. 18 we start with transfer functions for all loads and calculate the corresponding long term load distributions. We then calculate the stresses for each load separately. For each point considered we then get a number of stresses which are combined by the square root formula. This formula is correct provided we know the correlation factor $\rho$ between all stresses. Today we use zero correlation which is true for quite a few variables but not all of them. The uncertainties lie here in the correlation which is related to phase angles and simultaneous occurrence of different loads. Equivalent stresses are uncertain because the stress components $\sigma_{x} \sigma_{y}$ and $\tau$ are not in phase.

The second method is the "long term stress distributions". As shown in Fig. $19 \sigma_{x} \sigma_{y}$ and $\tau$ may individually be correctly estimated. These components are, however, not in phase and equivalent stresses are still difficult to obtain. Another difficulty is the necessity to perform a large number, say 200-300 stress calculations.

Thirdly, "dynamic equilibrium in regular waves" shown in Fig. 20 is in a way similar to the traditional approach considering a quasi static calculation in an equivalent wave, but the dynamics of the situation have been introduced and the phase angles between all loads are correct. This makes it possible to calculate equivalent stress as a function of time and find maximum for this stress.

Fourthly, "dynamic equilibrium in irregular waves" shown in Fig. 21 is similar to "Dynamic equilibrium in regular waves", but instead of regular waves we use a simulated irregular wave 
system. This method may be the most promising one because it is the only method which gives proper equivalent stress in irregular seas.

Both dynamic equilibrium methods have the great advantage in connection with the stress analysis that the loads are in equilibrium when they are applied to the structure. On the other hand, however, these methods give difficulties in connection with the choice of equivalent wave system.

As mentioned in connection with the square root method we have until now assumed zero correlation between the different variables. This means that they are considered statistically independent. We have, however, carried out some correlation studies and in Table 1 some results have been given. The correlation coefficient, $\rho$, has been found by solving the following type of equation

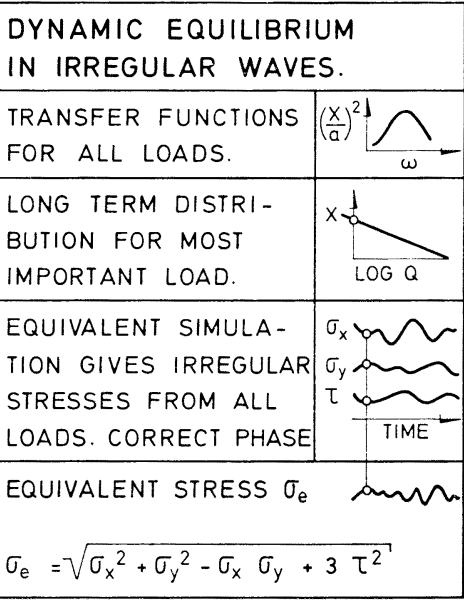

Fig. 21

$$
x^{2}=x_{1}^{2}+x_{2}^{2}+2 \rho x_{1} x_{2} .
$$

Here $x$ is the long term value of the sum of variables 1 and 2 found by taking the phase angles into account, while $x_{1}$ and $x_{2}$ are the individual long term values.

It is seen that particularly when considering internal and external loads on the bottom, the correlation is of great importance.

Table 1 Correlation coefficients Amidships, $F_{n}=0.2$

\begin{tabular}{l|c|c|c}
\hline \multirow{2}{*}{ Variable } & \multicolumn{3}{|c}{$L(m)$} \\
\cline { 2 - 4 } & 150 & 250 & 350 \\
\hline$M_{V}-M_{H}$ & 0.245 & 0.305 & 0.345 \\
$P_{e}-P_{i}$ & -0.77 & -0.75 & -0.74 \\
\hline
\end{tabular}

\author{
$M_{V}$ - vertical wave bending moment \\ $M_{H}$ - horizontal wave bending moment \\ $P_{e}$ - external bottom pressure, positive when \\ increasing \\ $P_{i}$ - internal pressure calculated from verti- \\ cal acceleration, assuming a full tank, \\ negative when increasing
}

\section{SESAM-69 Program, Recent Accomplishments}

The development of the Finite Element Method (F.E.M.) has during the last couple of years primarily been directed towards an increase in size and complexity of the problems to which the F.E.M. may be applied. Moreover, significant steps have been made in the area of implementation of largescale, general purpose, structural analysis programs such as NASTRAN, ASKA, STRUDEL, STARDYNE, EASE, DAISY, SESAM-69 and others.

These programs have made it possible to calculate accurately the mechanical response (deflections, stresses, vibration modes, temperatures, etc.) in complex structures, but often involving excessive computer expences. Computer time consumption is only one of the less attractive features of the conventional use of the F.E.M. Traditionally considerable manual efforts have been expended to initiate, check and interprete a finite element calculation.

Very few general-purpose programs have concentrated on reducing the man-and computer costs involved when applying the powerful F.E.M.

The multilevel superelement (or substructure) technique, however, in combination with extensive data generators as for example materialized in the general purpose program system SESAM-69 has in our opinion introduced significant attractiveness to the exploitation of the F.E.M. These features have 
been found to reduce greatly both man- and computer costs, and makes it feasible to solve very large and complex structural problems in an economical way.

By large problems in this context is implied static linear problems measuring more than one hundred thousand degrees of freedom and about the same number of basic finite elements, and a 1/50 factor lower for dynamic problems. According to our experience the man- and computer costs vary between $1 / 10-1 / 100$ of what would be the case if the conventional finite element programs not utilizing data generators and the superelement technique were used for this problem size.

\section{The multilevel superelement concept}

A first level superelement is a finite element covering any size and shape of a domain of a continuum, with any space variation in the material properties, internal loads, and internal constraints and any (large) number of external and internal degrees of freedom. The term "first level" means that the superelement is built up of basic elements only (zero level elements) in contrast to higher level superelements which may be built up of superelements from lower levels and basic elements. In this way a hierarchy of superelement levels may be introduced.

A superelement is often called a substructure, but more correctly it is a model of a substructure, or a single finite element representation of an arbitrary structural part.

A multilevel superelement program is a finite element program capable of producing superelement stiffness matrices and load matrices of any level, by application of the F.E.M. itself, from arbitrary lower level superelements.

It is then natural to ask: what is the intention of introducing these new concepts, and what are the advantages gained in the possibility of producing superelement?

Essentially this may be replied to as follows:

a) The preparation and checking of input data are simplified and shortened considerably. Structural parts such as membranes, shells and solids etc. may be treated as separate superelements and assembled to higher level superelements. The input for the different superelements may be prepared individually by different people.

b) Repetitive structural parts may be selected as superelements and described once. Thus their stiffness properties may be calculated once and stored in a superelement library for later use. This means considerable reduction in computer expenses and man-hours.

c) Modifications of configuration or reidealization in parts of a structure are inexpensive since only the affected superelements have to be reanalysed, the others will be collected from the superelement library in a restart run.

d) Very large problems may be handled accurately within single precision calculation, lowering computer expenses further.

e) The superelement method is general for any type of problem that may be formulated within the scope of the F.E.M.

For calculation of small problems (less than about 3,000 degrees of freedom) direct analysis programs (not using superelements) may presently be used efficiently. More complete descriptions of SESAM-69 may be found in Ref. 14).

An example of large-scale structural analysis of an oil tanker

The following example is a rather comprehensive stress analysis of the 191,000 t.dw. tanker "ESSO NORWAY". Preliminary results have been published previously15). This ship was chosen for analysis because very good full-scale measurements where available for comparison with the calculated results.

The purpose of this refined analysis was threefold:

- to show to which degree the finite element calculations with simple basic elements through the 
superelement method may reflect the measured stress response of a complex ship structure in detail, without resorting to a solution involving separate coarse and fine mesh analyses.

-to test the accuracy of the superelement technique working in single precision everywhere, except for accumulation of inner products in double precision.

- to test the multilevel program system SESAM-69 on large practical applications. The calculated response has been compared with full-scale deflection and gauge measurements carried out in July $1969^{16)}$.

Short description of element mesh in some parts of the finite element model

The static linear elastic analysis comprised superelements on seven levels giving detailed analysis of three cargo tanks in the midship section for half the ship breadth, Fig. 22. All primary members such as transverse frames, longitudinal bottom and deck girders, bulkhead stringers and vertical webs, have been included. Furthermore all stiffeners and brackets have been included as elements. The curved parts of the flanges on the transverse frames BENDING MOMENT AND SHEAR FORCE DISTRIBUTION.

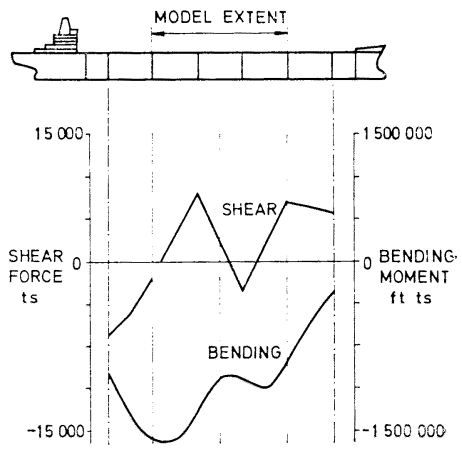

Fig. 22 and center girder frames have been modelled by shell elements, whereas the remainder of the structure has been modelled by membrane elements.

The number of different superelement types on each level were:

$\begin{array}{cc}\text { Level } & \text { No. of superelement types } \\ 1 & 42 \\ 2 & 6 \\ 3 & 8 \\ 4 & 1 \\ 5 & 1 \\ 6 & 1 \\ 7 & 1\end{array}$

The entire model comprises about 240,000 basic degrees of freedom and 145,000 basic finite elements. It is to be noted that the highest level corresponds to the entire structural model.

A typical transverse frame is shown in Fig. 23. The computer

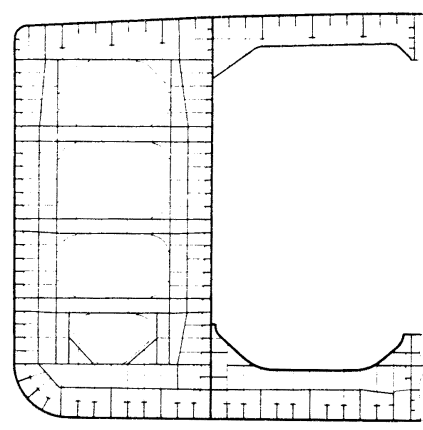

Fig. 23 plot of typical first level superelements in Figs. 24 to 28 show the idealization of the lowest part of

\section{COMPUTER PLOT}

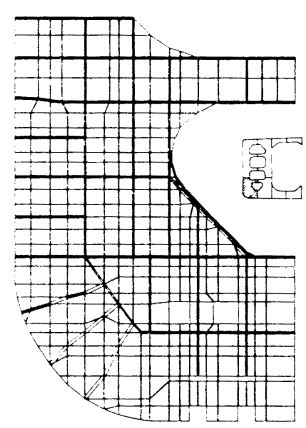

\begin{tabular}{|c|c|c|c|}
\hline \multicolumn{3}{|c|}{ K PLANE NO. 1 } \\
\hline $\begin{array}{l}\text { NV 339 3-DIM MEMBRANE ANALYSIS } \\
\text { SUP 1.7 }\end{array}$ & SCALE & & $27 / 11-i 1$ \\
\hline \multirow{2}{*}{$\begin{array}{c}\text { DET NIGN: HBRE } \\
\text { NORSKE VERITAS } \\
\text { COMPUTAS }\end{array}$} & $1: 50$ & APPR: & \\
\cline { 2 - 3 } & IN PLACF OF \\
\hline
\end{tabular}

Fig. 24 
COMPUTER PLOT

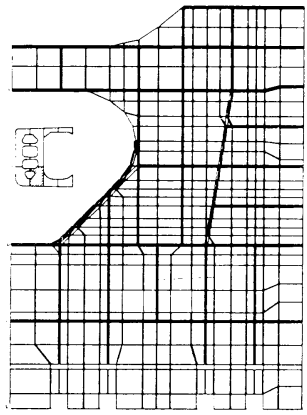

COMPUTER PLOT

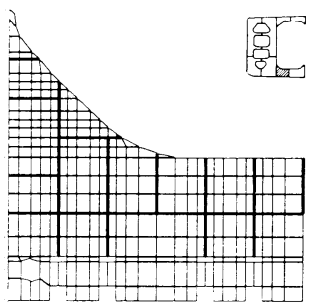

COMPUTER PLOT

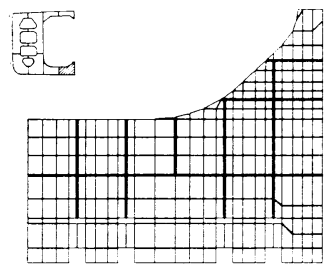

COMPUTER PLOT

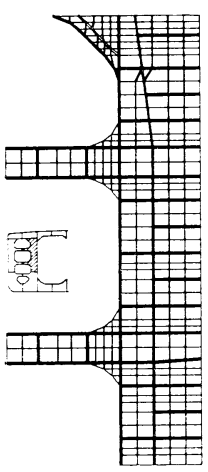

K PLANE NO.

\begin{tabular}{|c|c|c|c|}
\hline \multirow{2}{*}{$\begin{array}{l}\text { NV 339 MEMBRANE ANALYSIS } \\
\text { LOWER PART OF WEB. CT NEAR L. } \\
\text { BHD SUP 1.1 }\end{array}$} & SCALE & & $27 / 11-i 1$ \\
\hline \multirow{2}{*}{$\begin{array}{c}\text { DET NORSKE VERITAS } \\
\text { COMPUTAS }\end{array}$} & APPR: & \\
\hline IN PLACE OF & \\
\hline & REPLACED BY \\
\hline
\end{tabular}

Fig. 26

WEB-FRAME LOWER PART IN W.T.

NEAR L. BHD SUP 1.6

DET NORSKE VERITAS

COMPUTAS

REPLACED BY

Fig. 25

$K$ PLANE NO.

\begin{tabular}{|c|c|c|}
\hline \multirow{2}{*}{ SCALE } & & $2 \pi / 11-71$ \\
\hline & SIGN: RE & $25 / 7-71$ \\
\hline $1: 50$ & APPR: & \\
\hline
\end{tabular}

\begin{tabular}{|c|c|c|c|}
\hline & \multicolumn{3}{|c|}{ K PLANE NO. 1} \\
\hline \multirow{4}{*}{$\begin{array}{l}\text { NV } 339 \text { MEMBRANE ANALYSIS } \\
\text { LOWER PART OF WEB IN CT. NEAR } \\
\text { CL. SUP } 1.3\end{array}$} & \multirow{3}{*}{$\begin{array}{l}\text { SCALE } \\
1: 50\end{array}$} & & $27 / 11-71$ \\
\hline & & SIGN: AUG & $11 / 5-i 1$ \\
\hline & & APPR: & \\
\hline & IN PL. & $\mathrm{CE}$ OF & \\
\hline \multirow{2}{*}{$\begin{array}{c}\text { DET NORSKE VERITAS } \\
\text { COMPUTAS }\end{array}$} & & & \\
\hline & REPLA & CED BY & \\
\hline
\end{tabular}

Fig. 27

K PLANE NO

NV 339 MEMBRANE ANALYSIS

MIDDLE PART OF WEB. WT. SUP 1.9 APPR:

IN PLACE OF

DET NORSKE VERITAS

COMPUTAS

REPLACED BY

Fig. 28 


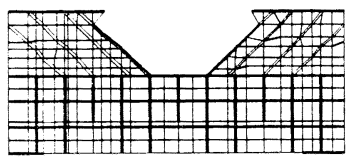

\begin{tabular}{|c|c|c|c|}
\hline & \\
\hline \multirow{4}{*}{$\begin{array}{l}\text { NV } 339 \text { 3-DIM MEMBRANE ANALYSIS } \\
\text { ESSO NORWAY } \\
\text { STRINGER } 1 \text { IN WING-TANK SUP } 1.14\end{array}$} & \multirow{3}{*}{$\begin{array}{l}\text { SCALE } \\
I: 85\end{array}$} & & $27 / 11-71$ \\
\hline & & SIGN: ENSEN & $27-8-71$ \\
\hline & & APPR: & \\
\hline & \multicolumn{3}{|c|}{ IN PLACE OF } \\
\hline \multirow{2}{*}{$\begin{array}{c}\text { DET NORSKE VERITAS } \\
\text { COMPUTAS }\end{array}$} & & & \\
\hline & \multicolumn{3}{|c|}{ REPLACED BY } \\
\hline
\end{tabular}

Fig. 29

the transverse web frames. Fig. 29 shows the idealization of the lowest stringer on the oiltight bulkhead in the wing tank. The number of nodes in every transverse web frame is about 3160 (indicating the typical half-band width of the system of linear equations to be solved, not using superelements.

A typical higher level superelement is shown in Fig. 30, being the third superelement type on the third level covering the lower part of three transverse web frames connected to the lower part of the longitudinal bulkhead and part of the stiffened bottom plating in the wing tank. Collecting the third level superelement types we obtain the fourth level superelement type number one covering one half open-ended tank length as shown in Fig. 31. On level five the superelement covers one tank length including the wash bulkhead and one oiltight bulkhead.

This describes in principle the assembly of various superelements for the midship part of a large tanker. The total extent of the model is shown in Fig. 22. When assembling the structure in this way the main rule is of course to minimize input work and computer time. In the design of superelements this implies a search for a subdivision that maximizes the possibilities of reproduction of the superelement types, and minimizes the band-width in the equations producing the superelement matrices.

The model extent for an analysis reflects the domain of interest for displacements and stresses. If the boundary conditions near the area of interest are known with the accuracy expected from the analysis, the model may consequently be limited to the area of displacement and stress in terest. This is generally not the case, and the model extent should be increased in accordance with experience to secure that errors in the distributions of boundary forces which may be produced from a simple beam calculation of the entire ship do not influence the results significantly.

In this case the boundary coditions for the finite element model were given by smoothened moment and shear force distributions obtained from a simple beam calculation of the entire ship.

The complete model extends over three cargo tanks with a reasonably fine mesh throughout. This can be achieved by repeating the superelement type covering one tank section with practically no increase in costs. This is cheaper than doing a coarse mesh analysis of the whole ship for the purpose of obtaining more accurate boundary conditions for a smaller fine mesh model. It should be mentioned 
that in this case the increase of man and computer cost extending the model from one tank section to three tank sections is about $5 \%$.

\section{Some results}

Due to lack of time only a small part of the calculated results have been studied at the time of delivery of the manuscript. A more detailed presentation of this analysis will be presented in Ref. 4).

The man time used for data preparation was 5 man months. Computer time for datacheck in this period was 2 hours CPU. Final computer time was 9.3 hours CPU, all on UNIVAC 1108 . The peripheral storage required for this analysis was about $1.5 \cdot 10^{7}$ words or four 2400 feet tape reels. The computer cost for this relatively large problem was N.Cr. 0.50 per degree of freedom being nearly independent of the number of load cases if less than 50. It could be mentioned for curiosity that the computer time to solve the same problem without use of the superelement technique would require about 440-520 days CPU time on the same computer. The demand on peripheral storage would measure $1.5-2 \cdot 10^{9}$ words or $350-4002400$ feet tape reels. This shows one of the advantages gained through the superelement technique, it moves the upper limit of computable problem sizes a significant step upwards. The numerical accuracy in the calculations is indicated by out-of-balance nodal forces measared to $10^{-5}$ of real nodal forces, thus indicating the possibility of doing the entire calculation in pure

NORMAL STRESSES

- - measured membrane stResses CALCULATED MEMBRANE STRESSES

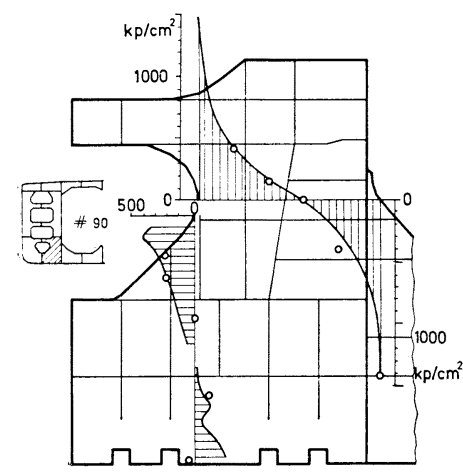

Fig. 32
NORMAL STRESSES

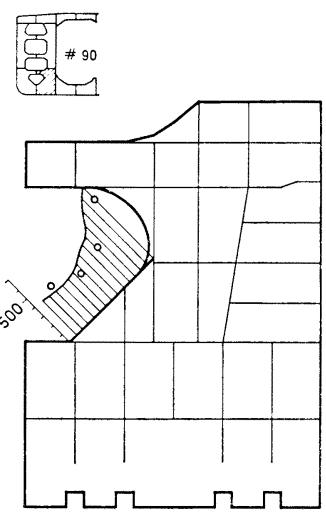

Fig. 33

NORMAL STRESSES

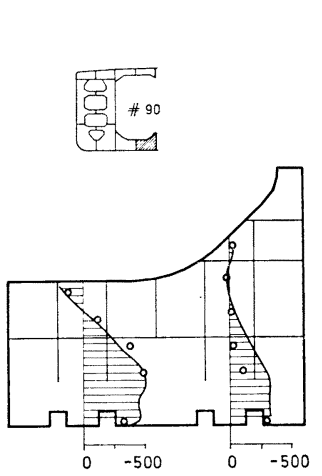

Fig. 36
NORMAL STRESSES

MEASURED NORMAL STRESSES ON EACH SIDE OF WEB

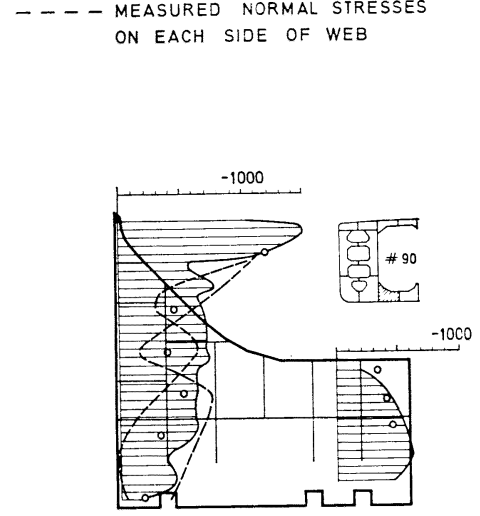

Fig. 34

NORMAL STRESSES

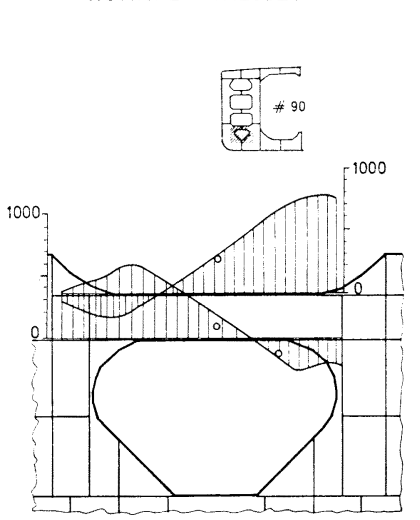

Fig. 37
NORMAL STRESSES AND

INITIAL DEFORMATION

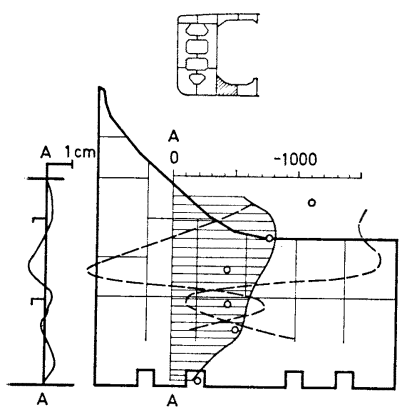

Fig. 35 
single precision and reducing the costs even further.

For comparison between measured and calculated stress components in the most heavily loaded tank, a few results have been presented in the following figures. Normal stress in the lower part of transverse web No. 90 has been shown in Figs. 32 to 37. Maximum shear stresses in some of the same sections have been shown in Figs. 38 to 40. Normal stresses in the central side girder in the wing tank

SHEAR STRESSES

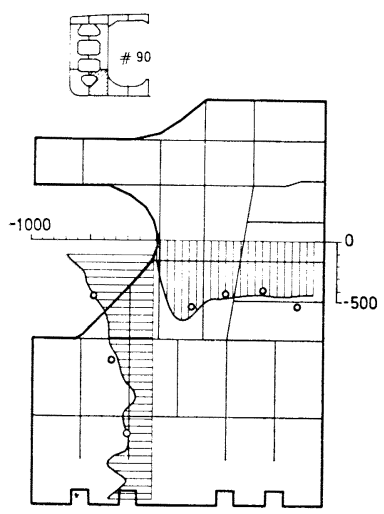

Fig. 38

SHEAR STRESSES

SHEAR STRESSES

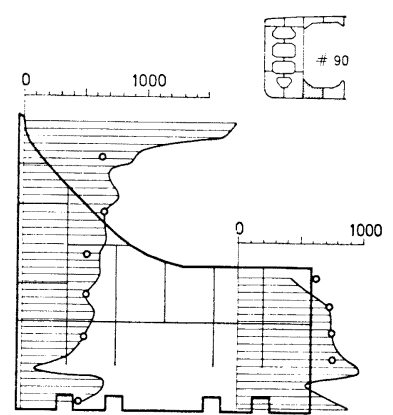

Fig. 39

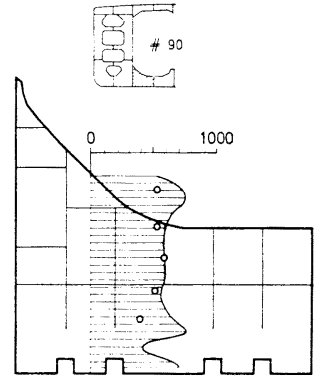

Fig. 40

have been shown in Fig. 41 and shear stresses in the wash bulkhead and oiltight bulkhead in Figs. 42 and 43 ,

NORMAL STRESSES

MIDDLE SIDE GIRDER IN WING TANK respectively. This is only a small part of the outcome of this analysis and even a small part of the measured response. Without having examined all stress components in all the 1400 measuring points and the associated calculated values at this time, we think that the accuracy of the analysis is fully satisfactory, showing a discrepancy of less than $10 \%$ on average compared with measured data.

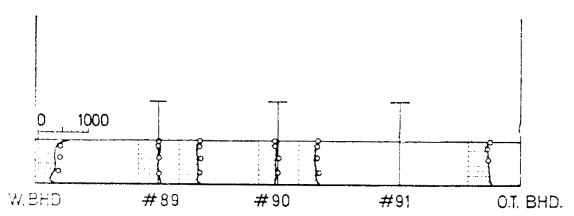

Fig. 41

It is interesting to notice that serious discrepancy occur in normal stresses in the transverse direction in web frame 90 near the longitudinal bulkhead in the center tank. This is a typical result of the difference between the linear elastic finite element analysis of a mathematically plane structural

SHEAR STRESSES

W. BHD. \#88

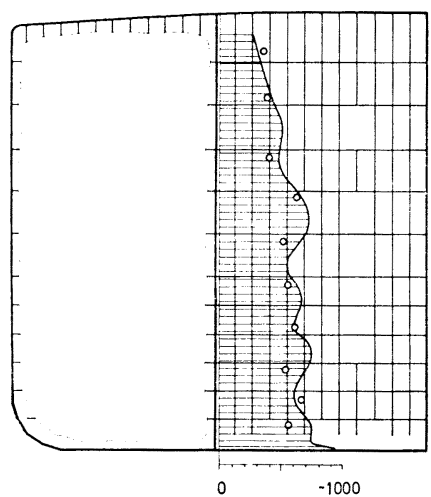

Fig. 42

\section{SHEAR STRESSES}

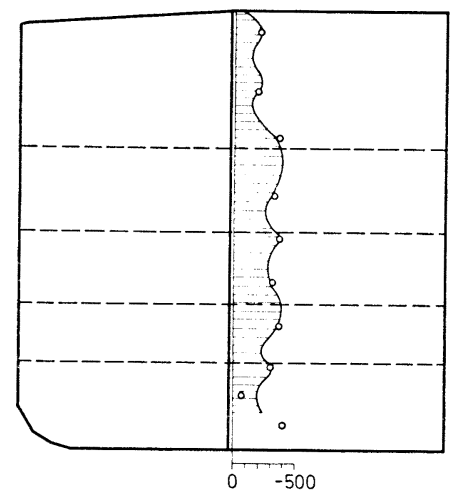

Fig. 43 
component, and the nonlinear but elastic buckling behaviour of the initially deformed unstiffened plate part being stressed in compression.

In Fig. 35 the measured normal bending stresses on each side of the plate is marked and shows that the plate bending stresses due to buckling is about 5 times the membrane stress.

To the left on Fig. 35 the initial deformations out of plane in section AA is shown. The redistribution of the loads in the structure according to this phenomenom, results in lower membrane stresses in the buckled area and higher membrane stresses in the surroundings, precisely what the comparison shows.

\section{Structural Design Aids}

In the context of our present rule book most structural parts may be designed with the aid of simple formulae. However, for some primary structures, e.g. transverse frames in tankers, this is not the case and direct structural analysis and stress criteria are normally applied. For plates and stiffeners etc., as well as the complete longitudinal structure the CBC-programs ${ }^{18}$ ) for tankers and bulk/OBO carriers are quite useful. By way of programmed rule formulas and evaluations of least weight alternatives to a certain extent they give scantlings and structural weights for a specified ship and structural arrangement. In our experience these programs are very valuable as initial design aids, especially since they give quite accurate steel weights on the basis of very simple input. However, usually we prefer to use the $\mathrm{CBC}$-programs in conjunction with stress analysis and design programs based upon stress analysis, since this gives more reliable weights for the primary girder structures and thus a more refined basis for choice between different structural alternatives.

The CBC-programs have recently been used for weight-analysis of various tanker arrangements in keeping with the present IMCO restrictions, weight as a function of various high-strength steels ${ }^{19}$, and other applications of interest to the shipbuilder. Further developments have also been made in the area of joint application of stress analysis and optimization techniques.

Thus the frame design program NV 382, originally developed at the Department of Ship Structures of the University of Trondheim, performs minimum weight design of two-dimensional in-plane frames subject to stress restrictions. Any kind of two-dimensional steel frames may be designed. The stress restrictions will be satisfied for all members (unless specified otherwise) in all load conditions. In addition several practical limitations, such as constant or equal height of some members may be included if desired. This method has given some very valuable results, especially as a basis for further evaluation of detailed stresses by the F.E.M. in the final, detail design phase.

\section{Torsional Analysis of Open Ships}

In modern container ships and other ships with wide hatch openings, the torsional rigidity of the hull may be so small that torsional deformations due to wave loads may exceed given acceptable limits unless special precautions are taken. Too large deformations may cause rapid wear of gaskets with subsequent leakages and/or structural damage in the hatch corners.

Similar problems may arise for other types of ships with large deck openings, e.g. gas carriers with large independent tanks protruding through the deck. It is of vital importance that the tank foundation and the tanks can absorb the interaction forces due to shear, torsion and bending of the hull girder as well as the interaction forces created by displacements of the local structural components.

In order to find effective solutions to these and similar problems, it is necessary to apply proper calculation methods with the possibility of including all relevant parameters in the mathematical model. The main features of programs NV 376/377 which are suitable for torsional calculations of open ships, 
are briefly described below.

The ship is divided into a suitable number of sections (maximum 20) depending on the longitudinal variation of torsional stiffness. The sections may be either open or closed, and the effects of double bottom and double sides are included. The computer program NV 37620) is based on the general warping theory of thin-walled beams, and it calculates the torsional properties and the relative variation of deformations and stresses over each section. The various sections are afterwards assembled to form a complete ship, and the solution is obtained by computer program NV 37721) by which kinematic and/ or static compatibility requirements between the sections are imposed. Structural elements which are not parts of the general cross sections, e.g. transverse deck strips and horizontal or vertical torsional boxes, may easily be taken into account.

The two programs thus produce nominal stresses and deformations due to a given loading. If a detailed evaluation of stresses is wanted in special regions, e.g. in the hatch corners, the displacements or forces obtained by NV 377 may be specified as input for a finite element model of the region in question.

A satisfactory calculation procedure for torsional response of open ships may thus be summarized as follows:

1) Calculate torsional properties of the various sections of the hull, NV 376.

2) Calculate nominal stresses and deformations of the complete hull, NV 377.

3) Investigate critical regions by the finite element method, with the results obtained in 1) and 2) as input.

By following this procedure, effective countermeasures to torsional problems may be taken at an early stage in the design process. Although these programs provide a rational tool for torsional analysis of hulls, it becomes increasingly attractive to employ the F.E.M. all the way, using a common structural model for stress analysis as well as for eigenvalues for the various vibratory modes.

\section{LNG-Carrier Design}

The various tools described previously in this paper are quite appropriate in conjunction with the design of advanced and complicated ships.

The design of Liquid Natural Gas (LNG) carriers is particularly challenging because of the special problems associated with the carriage of an inflammable liquid boiling at $-162^{\circ} \mathrm{C}$. Basically, this necessitates an extremely high reliability of the cargo containment system, since any failure of this will lead to brittle fracture of the hull and most probably to a complete loss of the ship. Two main problems areas are immediately apparent, viz.: structural behaviour and material properties. The former will be dealt with here.

The case to be discussed here describes a novel design concept, and what may be one of the most exhaustive design endeavours ever performed on the hull of a merchant vessel.

A general arrangement plan of the ship in question, an LNG-carrier is shown in Fig. 44. The basic design notion is founded on the principle of obtaining a primary barrier which has a reliability equal to or exceeding conventional combined systems of primary and full secondary barriers, viz.: 1) The tank (primary container) is to have a care-

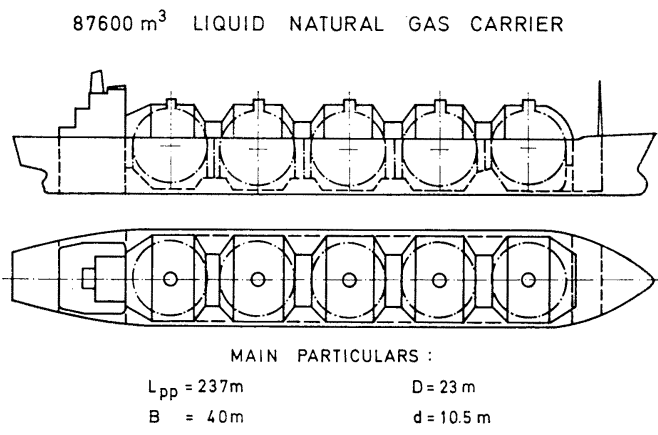

Fig. 44 
fully determined and acceptably low stress level in all regions and details.

2) The rate of crack propagation has to be determined. The growth of a minimum detectable crack during a specified time is to be determined.

3) The critical crack length of the tank regions has to be safely above the length of the maximum crack developed in the above mentioned specified period.

4) The tank is to be given a small leak protection system (reduced secondary barrier) which is able to take care of the largest leak the tank can develop for a specified time referring to conditions 1 and 2 .

Locally, the most important design criteria are in fact those associated with crack propagation rate and critical crack length of the material as described above. Globally, buckling is the decisive design factor. For this design the more or less empirical formulas for accelerations and wave loads were considered to be inadequate and were replaced by a complete analysis of the actual hull form response, short term and long term distributions of the various load parameters employing the methods previously described. As design parameters the maximum values of accelerations, torsional bending moments, shear forces etc. expected during twenty years of North-Atlantic service were chosen. For some important variables reference is made to Figs. 45 and 46.

LARGEST EXPECTED VERTICAL ACCELERATIONS IN 20 YEARS. FULL LOAD CONDITION

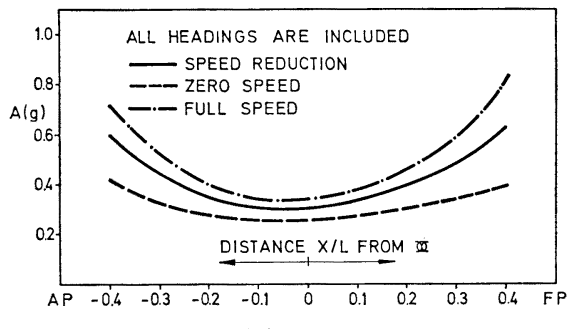

Fig. 45
LARGEST EXPECTED VERTICAL BENDING MOMENT IN 20 YEARS. FULL LOAD CONDITION

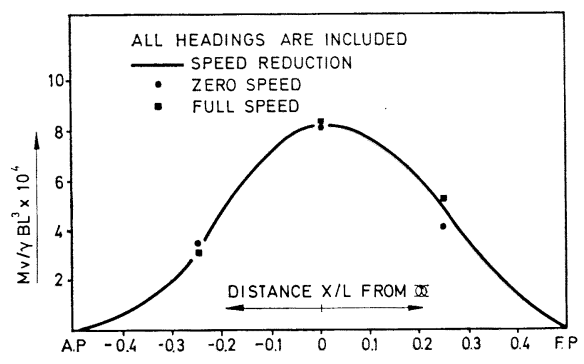

Fig. 46

The hull and tank response was analysed in three stages:

1) Longitudinal strength analysis (and torsional analysis) by means of beam theory.

2) Application of forces from 1) on a finite element model of part of the hull.

1) Coupling of tanks analysed by shell theory to the finite element analysis of the hull analysed by F.E.M.

The finite element model included two compartments, the compartment to be analysed and two other half compartments, fore and aft, see Fig. 47. Employing the superelement concept this means basi-

EXTENT OF MODEL FOR SYMMETRIC LOADCASES

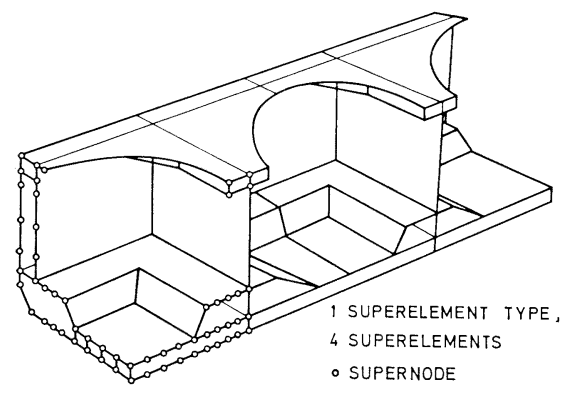

Fig. 47 cally that one quarter tank had to be modelled, whereas the remainder is simply repetition, or mirror images, of this basic part. Thus, any inaccuracies in the distribution of the forces introduced at the boundaries become negligible in the main central part of the model. As shown in Fig. 48 the model is rather coarse since it was only intended for displacement analysis of the hull, and not for detailed stress analysis. However, as shown in Fig. 49 the analysis also yielded valuable results with regard to the macro stress levels in the hull structure.

In addition to the finite element analysis of hull deflec- 
THE SUPERELEMENT TYPE EMPLOYED

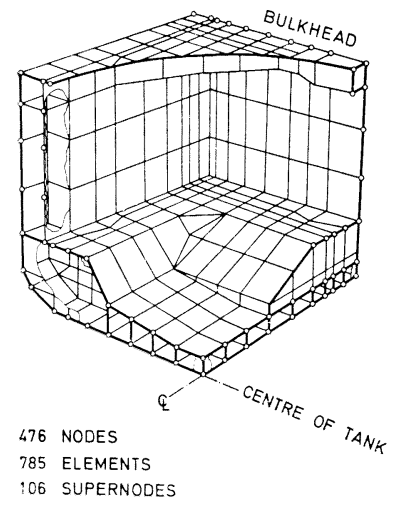

Fig. 48
LONGITUDINAL STRESSES IN MAIN DECK, BENDING LOADCASES

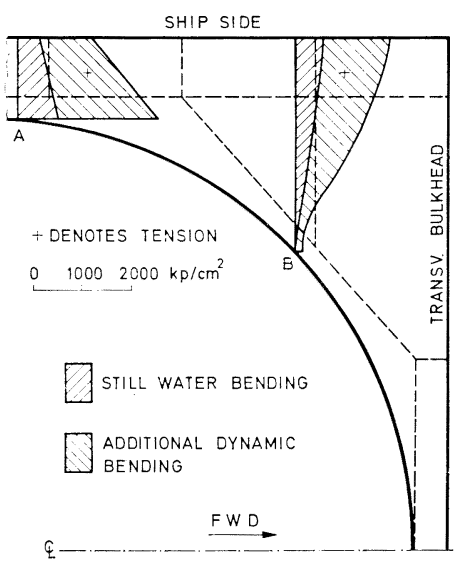

Fig. 49

tions the tank had to be analysed for sinusoidally distributed deflections along the bottom of the skirt (Fourier components). Then the coupling of the tank to the remaining hull was accomplished by means of the solution of a set of compatibility equations.

By employing the resulting coupling forces for the significant Fourier components the deflections and stresses in the tank itself was found. In addition the tank was analysed, by means of shell theory, for all the significant load cases as self weight, internal loads and pressure, etc. All relevant static and dynamic stresses were then combined by giving proper attention to phases.

The design incorporates one specially important structural detail, namely the connection between the skirt and the sphere. This stress concentration has been analysed in detail by means of both finite element models and photoelasticity. Good correlation was found between the two methods.

For both sphere and the stiffened cylindrical skirt buckling is the decisive criterion. The influence of imperfections on the ideal buckling load has of course to be accounted for. For the shell thickness ratios employed the influence of imperfections is considerable. The practical fabrication tolerances which have been established will in the extreme case give a reduction of $75-80 \%$ in the ideal buckling strength. This has of course been accounted for in the design.

\section{Propeller Induced Loads and Design}

It is evident that unfortunate propeller/afterbody arrangements are often responsible for intolerable vibratory levels in operating ships. This frequency results in cracking of hull structures, malfunction of essential propulsion components (e.g. propeller blade, propeller shaft), annoyance and discomfort to the crew. Reliable means for design and control of propulsor/afterbody configurations, when applied at an early state of planning and with proper attention given to prime parameters, are considered to be of the utmost importance. An interactive design scheme as sketched in Fig. 50 may thus be helpful.

The results obtained from block A in Fig. 50 will be the proper number of propeller blades, shafting system, engine cylinder number, firing order etc. These results

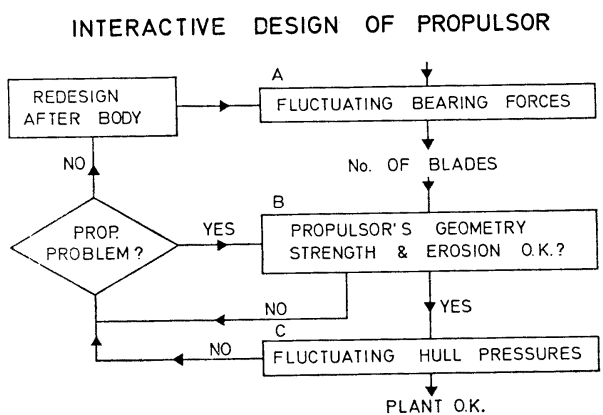

Fig. 50 
imply the avoidance of excitation of axial modes of vibration in the shaft/engine system for a given afterbody. At the same time excitation of shaft whirling should be kept below acceptable limits.

The propulsor's geometry is then subject to a "trial and error" process in block B. Finally block $\mathrm{C}$ provides information on the net vibratory energy transferred from the cavitating propeller to its adjacent boundaries. Vibratory energy transferred by opened up propeller tip--hull vortices in dead-

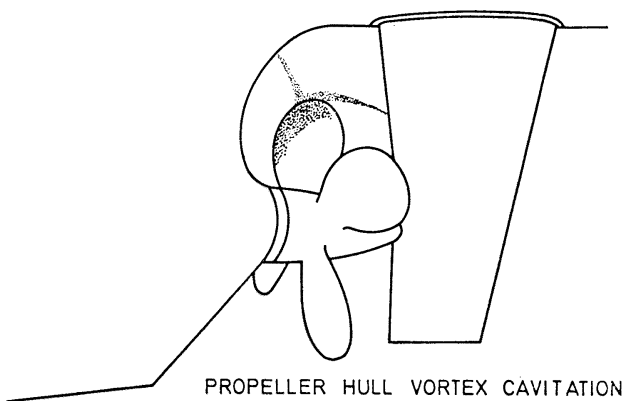

Fig. 51 water regions, i.e. at flow stagnation points on the hull, however, cannot at present be treated by theoretical or even semiempirical means, see Fig. 51, Huse $^{22)}$. Until this problem can be adequately taken care of, one should carry out careful flow studies in. critical regions of the afterbody at an early stage of each project.

Based on various attempts to design a propeller (Block B) one determines whether or not any propeller design is able to satisfy the requirements given in blocks $\mathrm{B}$ and $\mathrm{C}$-in the given wake. If not, the hull should be redesigned to produce a new wake picture and blocks $\mathrm{A}, \mathrm{B}$ and $\mathrm{C}$ be reconsidered.

Proper results for hydrodynamic loading particulars require the solution of a complicated lifting surface problem. With boundary layer effects included the downwash surface integral equation for a twisted wing of finite span should ideally be completely solved. The non-linear problem introduced by the boundary layer cannot at present be solved. Even when reducing the integral equation to static forces including drag and unsteady potential flow forces, we have experienced that the complexity of approach demonstrated by, e.g. Yamazaki23), does not match with the numerical techniques and computer speed available today. Both the random wake field and its periodic part should be employed in the computational procedures outlined in block A. The validity of Böes'2i) method for simplified treatment of the random wake field is questionable, since the propeller/hull interaction effects on the flow field may be significant. This method may prove useful, however, when applied to the local, effective wake. An analytical method, based on Lagally's steady motion theorem for estimation of thrust deduction, Beveridge ${ }^{25)}$ seems able to provide good correlation with experiments.

The procedure outlined in Fig. 50 is applicable to any propulsor system. Depending on the system in question and the involved hydrodynamic particulars, experiments are required to a smaller or larger extent. For example ducted propellers involve the use of vacuum tank van Manen ${ }^{26)}$, or a large cavitation tunnel Edstrand ${ }^{27)}$, with installed pickups to record vibratory pressures and forces.

Conventional propellers (single and twin screw) and overlapping arrangements on the other hand, lend themselves for study also by computerized methods. Various features of importance contained. within the blocks presented will now be considered in some detail.

\section{Hydrodynamic blade loading}

Obviously, most aspects of the interactive design process involves determination of the hydrodynamic propeller loading when operating in the behind conditions. Experience has clearly demonstrated that no method should be employed for prediction of such loading before correlating the theoretical aspects with relevant experimental results. In fact, reasonably simple theories may be employed for proper assessment of loading when combined with experimental data. Fig. 52 illustrates how some calculations match with recorded strains in the model of a propeller blade working behind a 220,000 t.dw. tanker. Included in the diagram is also the results of an "unsteady lifting-surface" approach, which, although is involves a detailed description of the unsteady potential flow forces, do not reproduce the experi- 
ments "within experimental accuracy", as does an alternative method. This method is based on a lifting line theory including effects due to finite chord distribution, curved flow in the wake as well as interaction between the hull wake and the propeller. Other verification substantiate the findings of the correlation study presented, Ræstad ${ }^{28)}$.

Fig. 53 gives an example of calculated versus recorded thrust for the model employed in the correlation study discussed above (Fig. 52). Full-scale recordings of thrust is compared with calculated values and are plotted in Fig. 54.

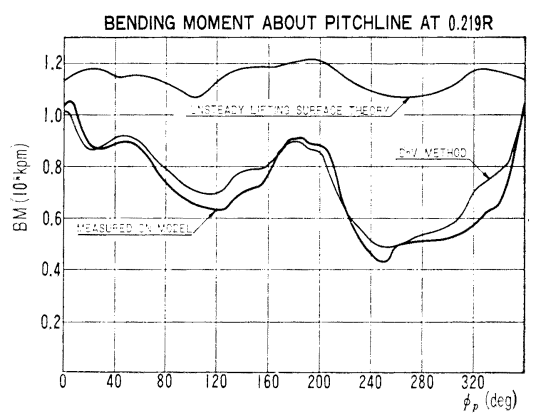

Fig. 52

THRUST VARIATION ON

A $220000 \mathrm{t} . \mathrm{dw}$. TANKER

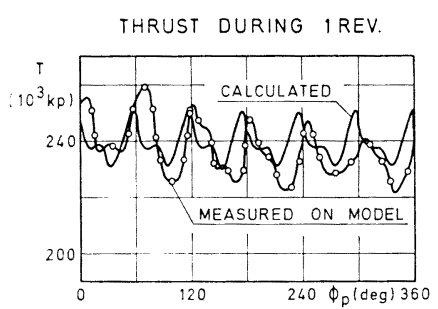

Fig. 53

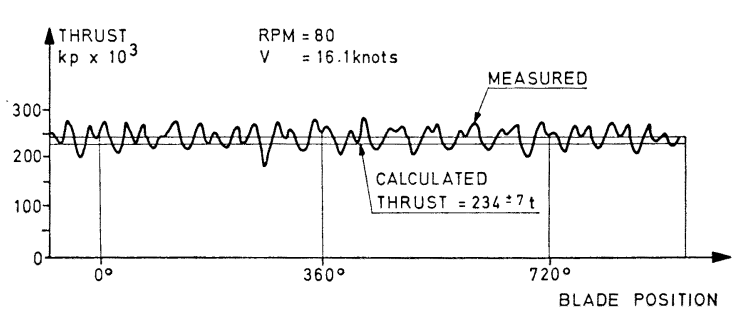

Fig. 54

Due to the large magnification factors involved when operating at axial modes of shaft resonance, the small thrust fluctuations exhibited in Fig. 53 and as calculated for a "dead" shaft (Fig. 54) should not coincide with resonance speeds.

Measured and calculated 6th order fluctuating bending moments in full-scale at the forward end of the propeller cone are plotted in Fig. 55. The figure illustrates how dynamic bending moments in the shaft increase in an exponential fashion due to dynamic response when the RPM approaches a whirling resonance. In extreme cases these fluctuating bending moments may lead to fatigue damage of the propeller shaft as well as to significant dynamic bearing reactions.

Although the scale effect on the mean wake at the propeller plane is of great significance, model and full-scale measurements of fluctuating loadings transferred to the shaft indicate that there is little effect of scale on the so-called fluctuating bearing forces, Schwanecke ${ }^{29}$ ) and Vedeler ${ }^{30)}$.

The above conjectures are concerned with the ship operating in

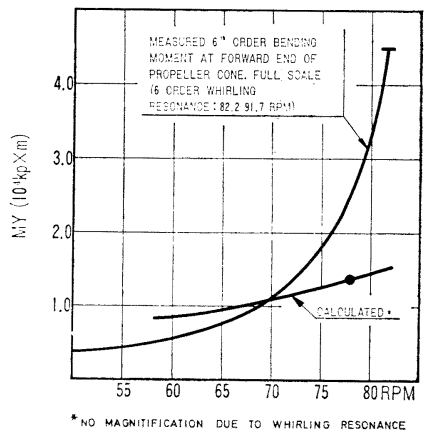

Fig. 55 calm water. The irregular motions between propeller and water particles in a sea way will of course influence the hydrodynamic loading of the propulsor, Nordenstr $\phi \mathrm{m}^{31}$.

Two types of wake fractions are assumed to be caused by relative motion between propeller disc and wave. Type one is the first order tangential wake fraction caused by the propeller plane relative motion between propeller disc and wave.

Fig. 56 presents the amplitude of the relative velocity occurring at the probability level $Q=10^{-8}$ (North-Atlantic) as a function of the ship's length, speed corresponding with Froude number $F_{n}=0.2$ and block coefficient $C_{B}=0.6-0.8$.

This velocity $V_{R_{\max }}$ is the vector sum of the pitch component $V_{p}$, the heave component $V_{H}$ and the 


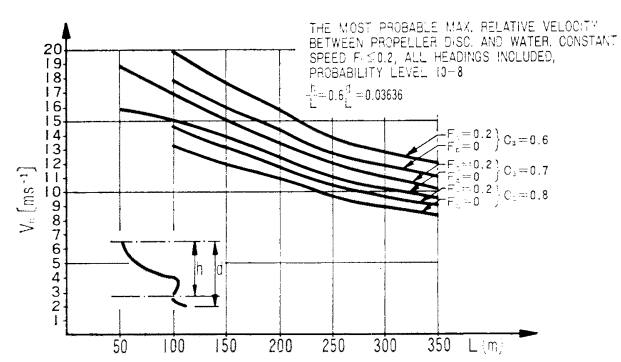

Fig. 56

wave amplitude component $V_{\text {wave }}$ so that:

$$
V_{R_{\max }}=V_{p}+V_{H}-V_{\text {wave }} \text {. }
$$

It may be shown that the ship through $N$ revolutions of the propeller shaft experiences a vertical velocity $V_{R}$ which is equal to or slightly greater than:

$$
V_{R}=-V_{R_{\max }} \frac{\log _{10}\left(N / N_{p}\right)}{\log _{10} N_{w}}
$$

where:

$N_{p}=$ total number of propeller revolutions during the

ship's lifetime

$N_{w}=$ total number of wave encounters during the ship's lifetime.

A representative magnitude of $N$ is chosen in accordance with the purpose. We may experience a wave induced radial stress during one revolution as illustrated in Fig. 57.

Type two of the wake fraction is the wave modulated axial wake fraction observed during experiments. This is caused by the relative horizontal motion between the water particles and the propeller disc. The resulting load on the blading therefore matches the frequency of wave encoun-

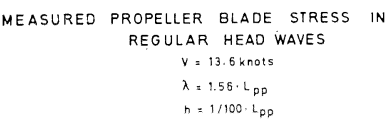

ter, see Fig. 58, and Sóntvedt ${ }^{32}$ ).

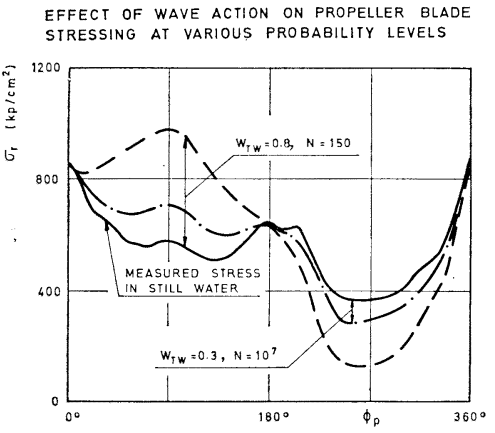

Fig. 57

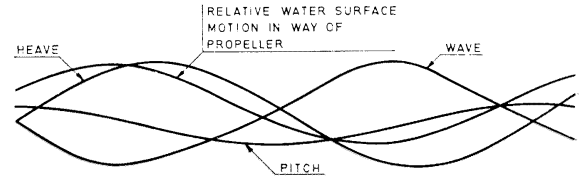

PROPELLER BLADE STRESS AT $T=03 R$

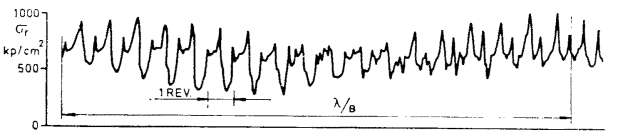

Fig. 58

It is fair to say that the above indicated procedure for determination of wave effects together with rough prediction of scale effects on the hull boundary layer today represents a well substantiated

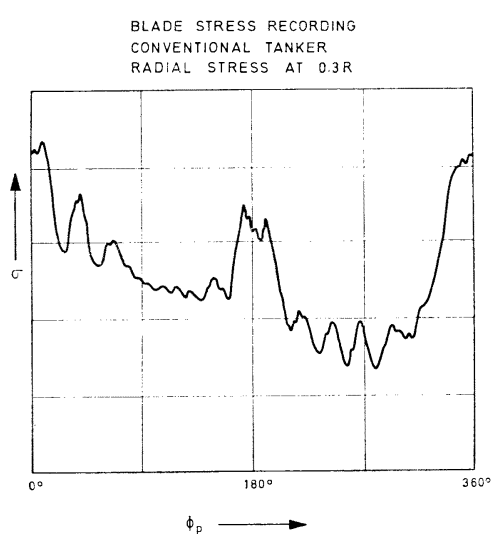

Fig. 59 method for prediction of realistic operating conditions for any propulsor.

\section{Dynamic response of propeller blade}

Failure of propeller blades is no doubt connected also with excitation of various natural modes of vibration of the blades. The limited amount of full-scale data available illustrates that it is difficult to avoid excitation of the lowest flexural mode by fluctuating hydrodynamic loading or propeller shaft motions. Figs. 59 and 60 present full-scale blade stress recordings for a conventional tanker propeller (220,000 t.dw.) and a ducted propeller system $(220,000$ t.dw.), respectively. In both cases the high frequency part of the fluctuating stresses corresponds with the fundamental mode of flexural vibration. For high speed 


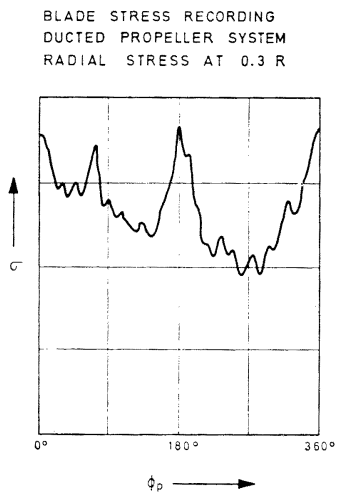

Fig. 60

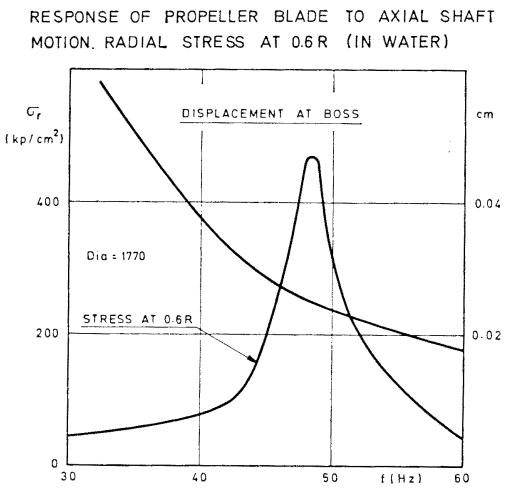

Fig. 61

ships (21-35 knots) this part of the fatigue action in the blading (which apparently is difficult to avoid) may represent a severe problem.

By proper investigations at the design stage, forced oscillations of the blades caused by shaft motions may be avoided (Block A). No doubt, torsional, whirling and axial modes of shaft vibrations with frequencies matching with (or even away from) flexural reasonance in the blades may introduce conditions leading to reduced material life. Fig. 61 illustrates how large stress amplitudes in the blade may be induced by small axial displacement amplitudes of the propeller shaft. The experiment illustrated in Fig. 61 has been verified by calculations, Sóntvedt $\left.{ }^{33}\right)$.

\section{Propeller cavitation as a source to erosion and vibration}

The propeller may interact with dead water regions in the afterbody and produce tip-hull vortex cavitation pulsating with the frequency of RPM times number of blades, see Fig. 51 and Huse ${ }^{22}$.

The pressure fluctuations on the hull near the propeller may then attain magnitudes as those sketched in Fig. 62 (full-scale condition). By proper flow studies at the design stage we are left with propeller induced pressure impulses caused by pulsating cavities when moving through hull wake peaks. Fig. 63 demonstrates that the non-cavitation propeller induces small pressure fluctuations on the hull and

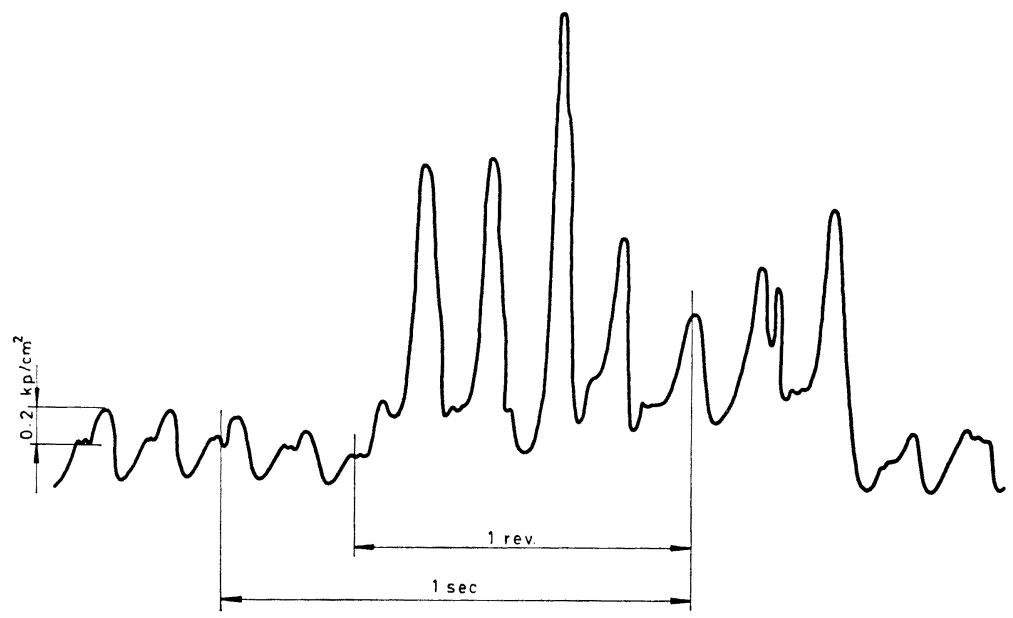

Fig. 62 
CAVITATION OCCURS WITHIN \pm 45 DEGR. WITH UPWARDS VERTICAL

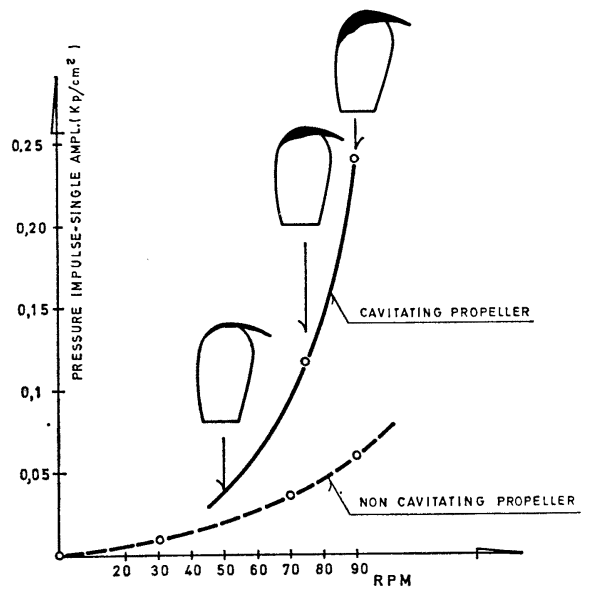

Fig. 63

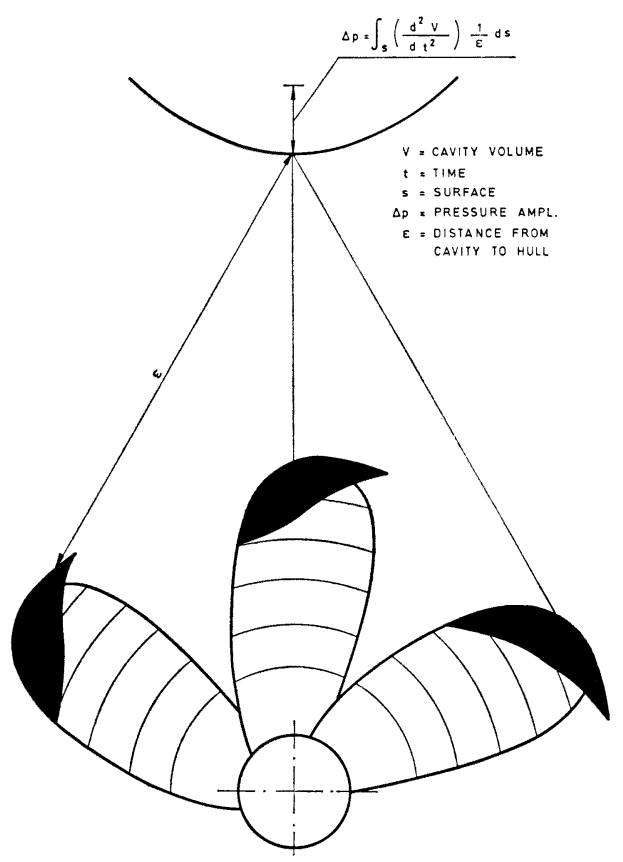

Fig. 64

adjacent appendages. As the amount of unstable blade cavity volumes increases with increasing blade hydrodynamic loading, the pressure fluctuations may be observed to increase rapidly towards large magnitudes. Since cavity implosions cause the fluctuating hull pressure field to operate in phase, the net force transfer to the hull may attain values $30-40$ times larger than those caused by the noncavitating propeller.

A method for assessment of the vibratory output from the cavitating propeller has recently been completed, Holden and S $\phi$ ntvedt $^{34}$ ). The diagram in Fig. 64 briefly indicates fundamentals of the approach involved.

When calculating the type and extent of cavitation, the first step consists in assessing the spanand chordwise blade pressure distribution, see Figs. 65 and 66. For determination of the chordwise pressure distribution an aerodynamic theory Holden ${ }^{35}$ ) for swept wings of small aspect ratios is used. This theory has been modified and extended in accordance with the operating conditions for a propeller blade taking into account the curvature of the inflow streamlines when operating in a wake field. The center region pressure in the free vortices shed from the blade, (or bubble formation due to leading edge separation), then form the basis for estimates of type and extent of cavitation in open

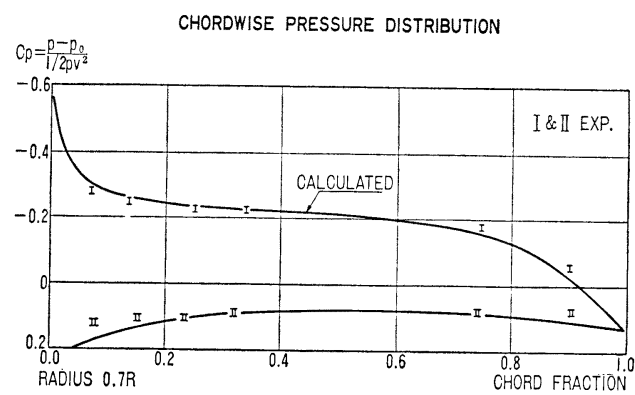

Fig. 65

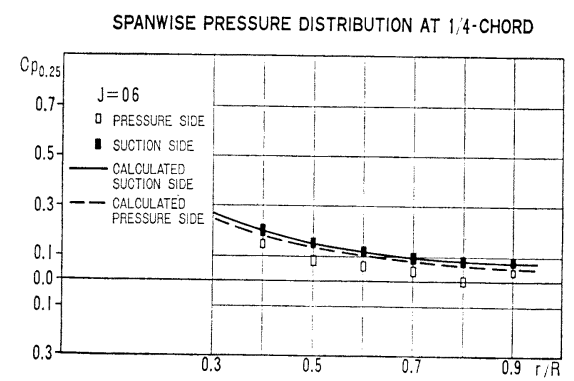

Fig. 66 


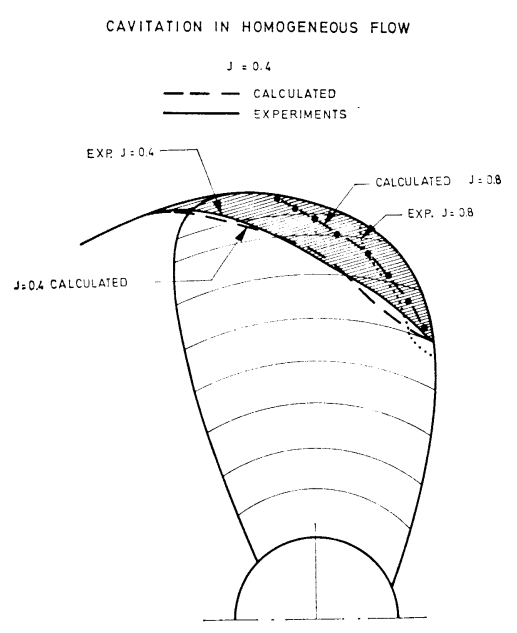

Fig. 67

water, see Fig. 67 and in real behind conditions, see Fig. 68.

These types of calculations have been verified by several experiments ${ }^{35}$ ). Note that when performing studies on the said features, full-scale behaviour is determined by intro-

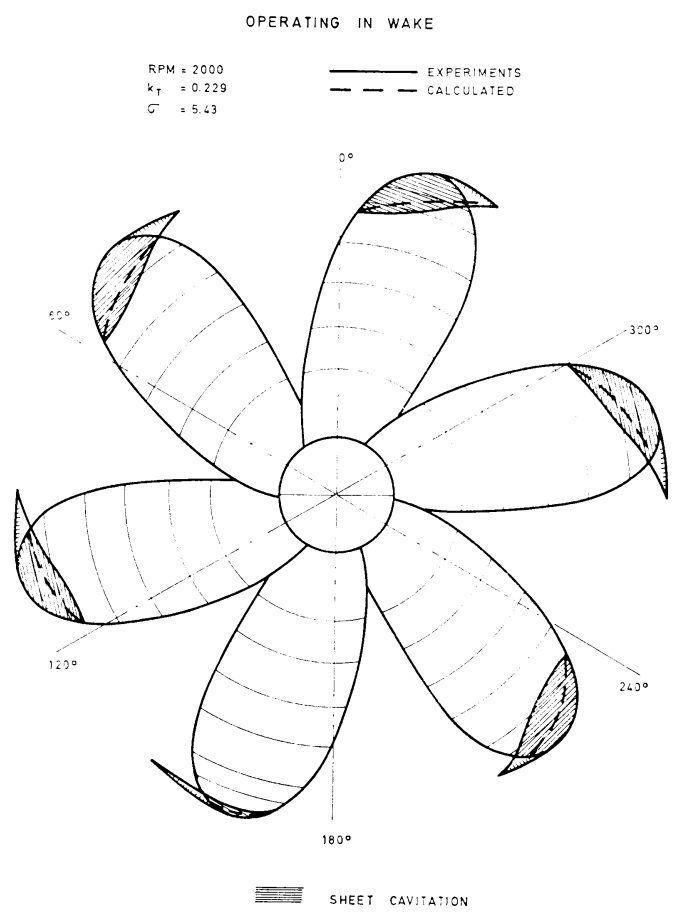

Fig. 68 duction of scale factors ${ }^{28)}$. Further, wave action is taken into account. Fig. 69 shows an example of full-scale recordings of pressure fluctuations on the hull when operating in waves.

The erosion mechanism related to cavitation is greatly influenced by the type of cavitation. Apparently, the rate of collapse will greatly determine acceleration periods and steady state erosion. For example, heavily separated flow with no reattachment within the profile length will greatly facilitate instantaneous cavity collapse near the blade trailing edge. Bubble formation as well as the said sepa-

PRESSURE IMPULSES IN STILL WATER
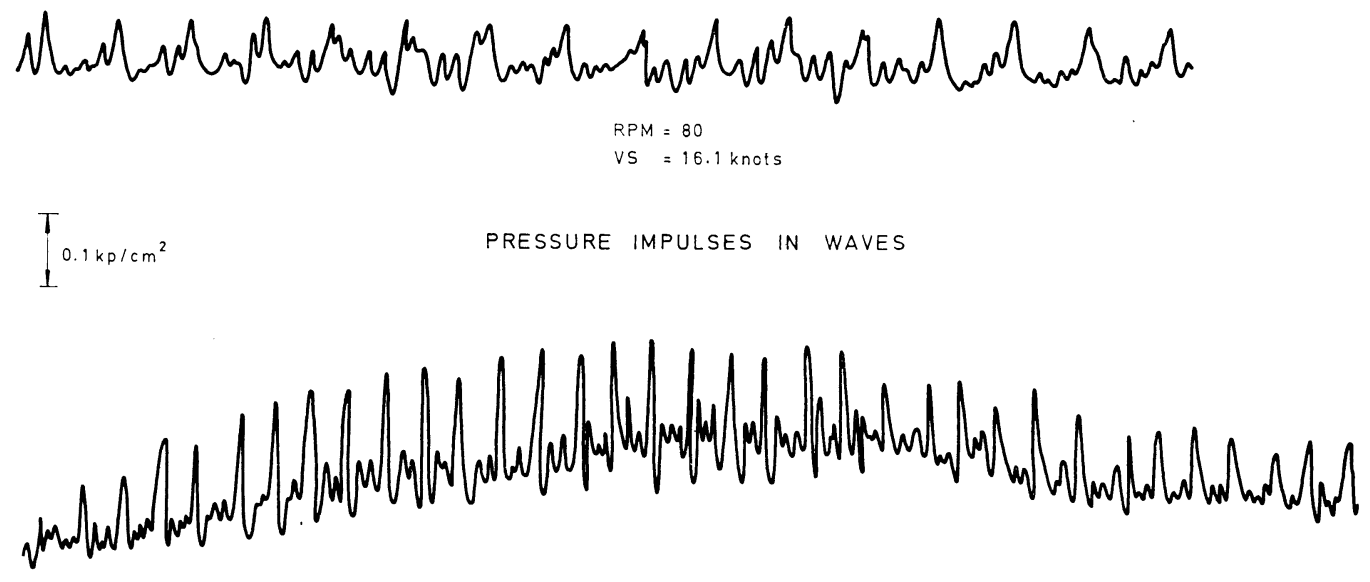

$R P M=80$

VS $=16.1 \mathrm{knots}$

Fig. 69 
rated flow may be determined at the design stage by the procedure given in 35). We will not fail to mention that the erosion mechanism described above may lead to greatly reduced fatigue life of the blade material.

\section{Interaction between Hull and Machinery Structures}

The structural design of the machinery area in hulls of large ships, seatings, engine framing, etc. have to a large extent been based upon empirical data, and the design criteria and tools have not kept pace with the advances made in structural design at large. The main reason for this has been the lack of appropriate methods capable of handling such complicated structures and the involved system of forces acting upon them. Relevant criteria for permissible forces, stresses and deformations are also to a large extent missing. This situation is now rapidly changing with the practical advances of finite element methods in ship design.

For illustrative purposes two cases of datailed structural analyses of engine room structures will be described briefly in the following.

\section{Turbine installations}

The majority of damages experienced with marine main turbine reduction gears during the last 15 years, i.e. pittings, scuffing, dedendum grooving wear and tooth breakages, may frequently be related to effects of non-uniform load distribution across the face of the teeth. This may in turn be caused by internal misalignment between gear elements and shafting, elastic deformation of the pinion or by thermal effects.

In spite of the more or less satisfactory verification of gear tooth contact before and after sea trials, experience has shown that a relatively great number of gear failures are associated with the dynamic interaction between hull structure and transmission system, causing non-parallelism of pinion and wheel axes under varying operating conditions.

The relative movements of hull structure and transmission system may influence the main gearing in three different ways:

1) Changes in alignment between turbines and first reduction pinions under varying operating conditions may exceed allowable limits and cause damages to first reduction gear elements, bearings and tooth couplings.

2) Deformations of the double-bottom and thrust bearing may affect the line shaft alignment in such a way that bending moments are introduced into the gear, causing large uneven bearing reactions, distortions of gear casing and misalignment of pinions and wheel.

3) Deformations of the double bottom under varying loading conditions and seaways may impose external forces on the gearcase through the gear foundation. The resulting gear case deformations, which in turn may affect the internal alignment between pinion and wheel, will depend on the stiffness of the gear case as well as the type of support.

From a structural point of view, there are two main problems to be analyzed: The deformation of the gear casing, which is induced by bearing reactions and temperature changes within the casing, and the effects of the deformation of the ship's double bottom.

For a $280,000 \mathrm{t} . \mathrm{dw}$. tanker these problems have been approached by the finite element technique. The structural parts of the afterbody in way of the engine room were modelled using a total of about 8000 membrane and bar elements. The extent of the model is shown on Fig. 70, and a typical section of the model is shown in Fig. 71. The model extends from the engine room to the fore part of the aft cargo tank, and comprises double bottom, thrust-bearing and gear foundations, gear casing, sides and decks including the upper deck and bulkheads. Still water dending moment and shear force 


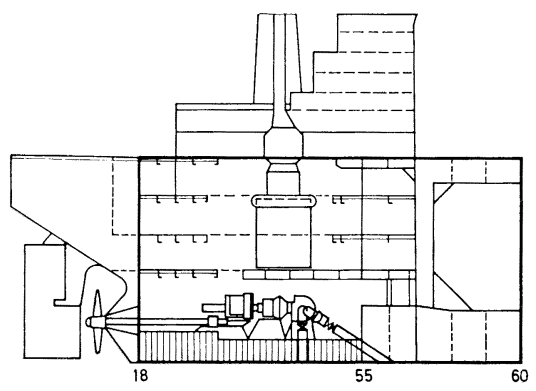

Fig. 70
SECTION IN ENGINE ROOM OF FINITE ELEMENT MODEL

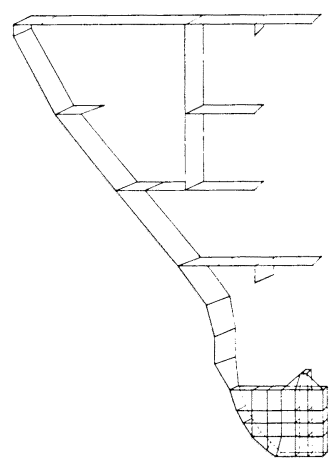

Fig. 71

obtained from the longitudinal beam analysis were distributed at the aft end section of the model. The following individual load cases were investigated:

Gear casing:

I. Bearing reactions corresponding to $100 \%$ torque.

II. Unsymmetrical bearing reactions in the second reduction gearing.

III. Temperature variations within the casing.

Double bottom:

I. External hydrostatic pressure (trim included) and loading of ballast and cargo tanks in light-, ballast- and full-load conditions.

II. Thrust force acting on the thrust foundation.

Hull steel weight and weight of machinery were included.

Fig. 72 shows computed vertical deflections of the double bottom structure in the ship's centerline, in ballast and full-load conditions. Various local deflections might also be studied in detail.

VERTICAL DEF. AT TOP OF CENTERGIRDER IN ENGINE ROOM

\section{Slow speed diesel installations}

There is a consistent lack of information on the interaction between double bottoms and machinery in propulsion installations with large slow running engines. Howerer, the following problems are well known:

-Inadequate connections between engine bedplate and seating causing the engine to work loose and subsequently wear down the chocks.

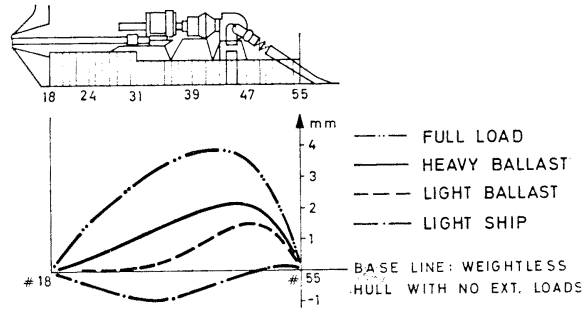

Fig. 72

-Development of misalignment of shafting system, including crankshaft and tailshaft.

-Double bottom and engine deformation due to sea load resulting in cracked structural members and trouble with the bearings of the running gear.

-In addition to problems associated with externally imposed loads, other originate from internal forces, gas forces components, externally unbalanced mass force and internal forces and moments.

-It is well known that these pulsating forces may introduce serious vibrations in the ship's structure.

The assumption of a "stiff" engine structure is not adequate to deal analytically with these problems. The finite element analysis opens the possibilities for integral structural analysis including the machinery structure and the machinery section of the hull. The engine may be modelled in sufficient detail to reproduce its elastic response to internal and external effects, and placed on the bottom. 
ROUGH SKETCH OF FINITE ELEMENT MODEL

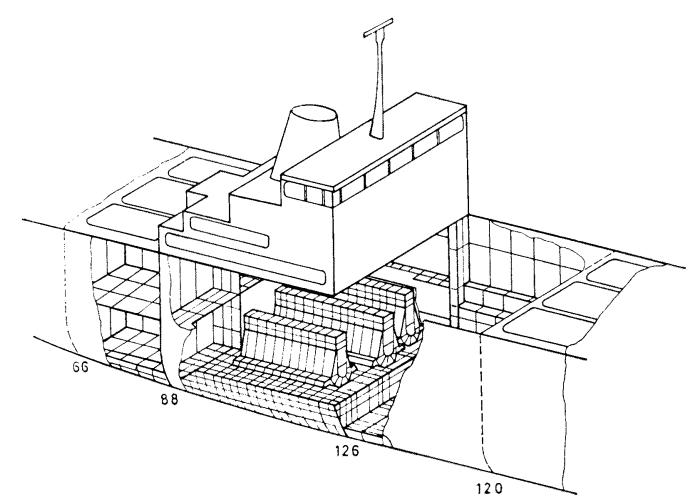

Fig. 73

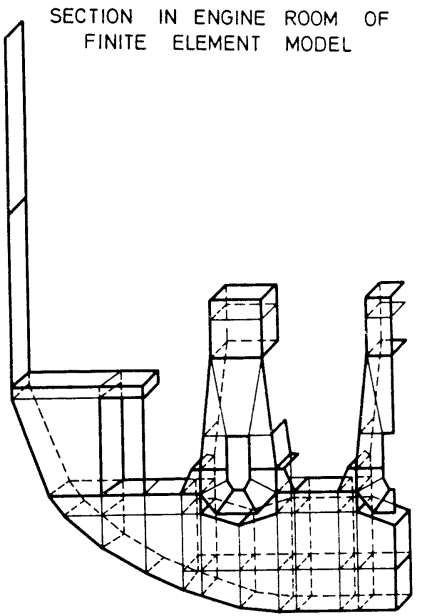

Fig. 74

structure which is modelled in a similar way. In the following is described an element analysis carried out on a 3 -engine installation of a container ship.

The model extends half-way into the cargo holds at each side of the engine room, and includes double bottom, sides, decks and main engine structures, see Fig. 73. The structural parts are thus represented by a total of 4274 membrane elements connected at about 2000 nodes, see Fig. 74 , showing one section. This finite element mesh was chosen to give a reasonable representation of the stiffness properties of the structure. For a more accurate stress analysis, however, a finer element mesh would be required.

The forces acting in ballast and full-load conditions were applied to the model, i.e. external hydrostatic pressure (trim included) weight of containers and loading of tanks. Hull steel weight and weight of main engines were included. Still water bending moment and shear force as obtained from the longitudinal strength calculation were distributed at the aft end section of the model. Forces originating from the engines were included as separate load conditions (1st and 2nd order mass force distribution).

The following figures illustrate some of the findings. Fig. 75 shows computed vertical deflection of the double bottom structure in the ship's centerline, in ballast- and full-load conditions. The basis line used as reference, represents a weight-less hull with no external loads. The double bottom structure in the engine room is very rigid as compared to that used in cargo spaces. Consequently, only

VERTICAL DEFLECTIONS OF TOP OF CENTERGIRDER

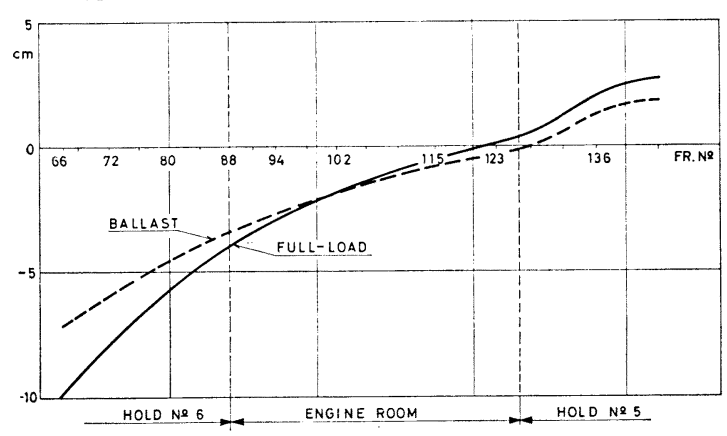

Fig. 75

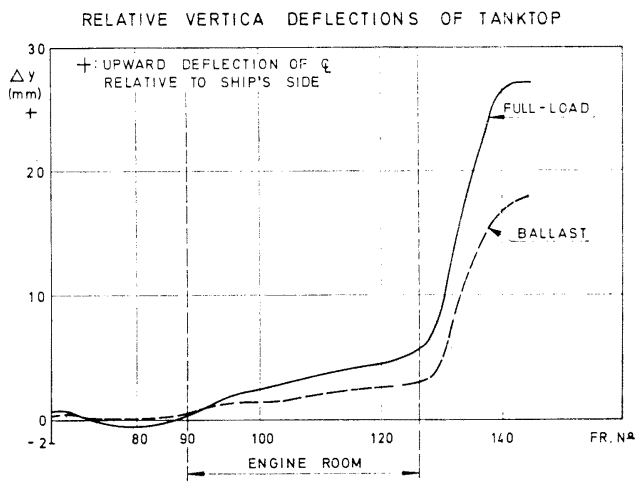

Fig. 76 
a small curvature is detected in this area, increasing rapidly toward the cargo holds. Fig. 76 shows; the corresponding relative vertical deflection of the tank top between the ship's side and the centerline (relative to the ship's side). Because of the abrupt change in double bottom height when moving. forward from the machinery into the cargo spaces, the center areas of the cargo hold tank top (relative to the ship's side) has a large deflection upwards in both loading conditions. This effect extends into the fore part of the engine room. Fig. 77 shows vertical deflections of the main bearings in.

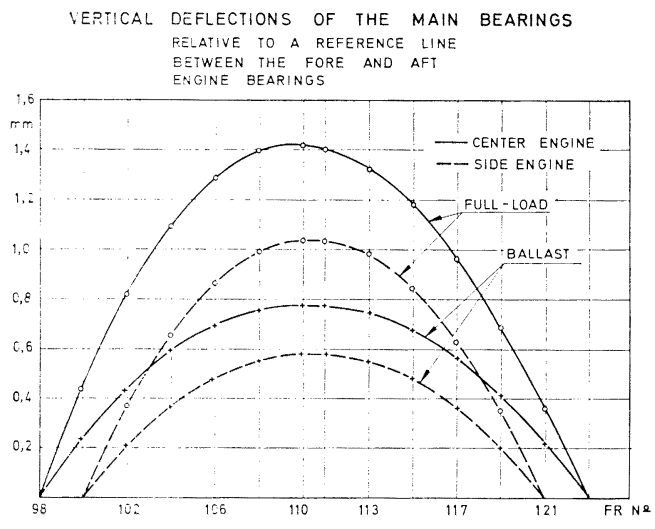

Fig. 77

ballast and full-load conditions for center and side engines, the offsets are plotted relative to a reference line between the fore and aft engine bearings. Fig. 78 shows vertical deflections of the tank top at the side girder beneath the inner foundation of the side engine.

The offsets are plotted relative to a reference line between the fore and aft engine room bulkhead. The separate influences of engine weight and loading of the ship are shown. Fig. 79 presents some of the computed reaction forces acting in the connection between the side engine and its foundation. Rigid connection between each engine and the foundation is assumed.

Values for the following load cases are shown: -Increase of draft from ballast to full load.

-Engine bearings loaded by inertia forces.

-Engine structure loaded by guide forces.

(4th order component).

As shown in Fig. 79, the forces arising from the latter load case are rather small. However, this type of loading frequently may excite transverse vibration of the engine structure (for instance X-vibrations of the engine top), which introduce dynamic magnification factors in the order of 10 to 20 . This indicate the necessity of extending the analyses to indicate dynamic response of the engine room structure.

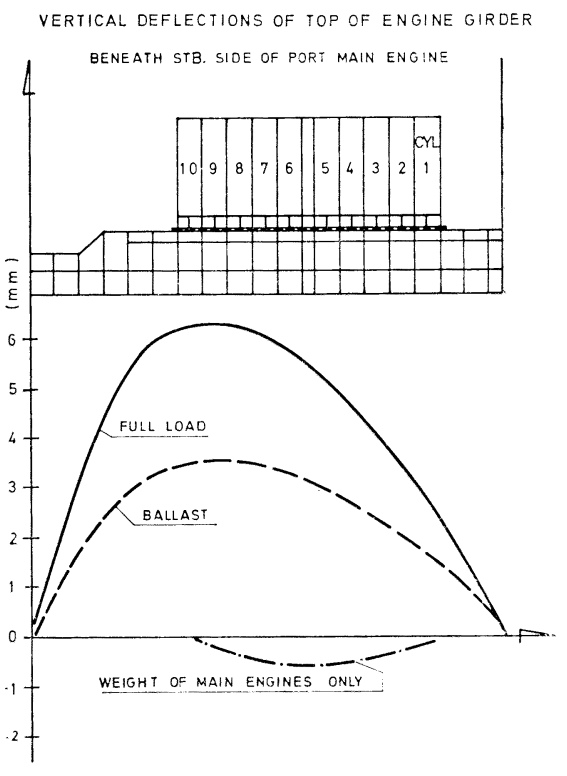

Fig. 78

COMPUTED REACTIONS (TONS)

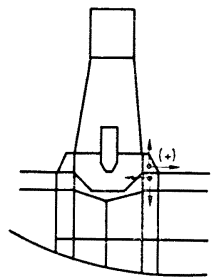

TRANSVERSE DIRECTION:

\begin{tabular}{|c|c|c|c|c|c|c|c|c|c|c|c|c|}
\hline EN & 12 & 11 & 10 & 9 & 8 & 7 & 6 & 5 & 4 & 3 & 2 & 1 \\
\hline A & 17.1 & 14.5 & 17,4 & 20,0 & 21,2 & 16,7 & 18.0 & 19.7 & 17,6 & 15.9 & 12.7 & 8,7 \\
\hline$B$ & 11,2 & 3.7 & -0.8 & $-5,2$ & 2,2 & 5.6 & -11.9 & -17.7 & $-36,1$ & $-20,0$ & 13.1 & 18,8 \\
\hline C & -0.1 & -0.5 & $-0,3$ & $-0,1$ & $-0,3$ & -0.3 & $-0,3$ & 0.3 & 1,3 & 1.2 & 0.9 & 0.3 \\
\hline
\end{tabular}

VERTICAL DIRECTION:

\begin{tabular}{|c|c|c|c|c|c|c|c|c|c|c|c|c|}
\hline PRASE & 12 & 11 & 10 & 9 & 8 & 7 & 6 & 5 & 4 & 3 & 2 & 1 \\
\hline A & -1.7 & 22,2 & 22,3 & 17.4 & 13.0 & 8.3 & 6.7 & 11.6 & 13,6 & 22.1 & 24.4 & 13.7 \\
\hline B & -20.3 & 8.3 & 40.6 & 15.9 & -4.9 & -6.1 & -24.8 & -42.0 & -15.3 & 28.8 & 22.4 & -4.4 \\
\hline C & LESS & THAN & 0.3 & TONS & & & & & & & \\
\hline
\end{tabular}

A: VARIATION FROM BALLAST TO FULL-LOAD CONDITION

B: BEARING LOADED BY 1ST. AND 2ND. ORDER MASS FORCES, AT CRANK SHAFT POSITION GIVING MAXIMUM VERTICAL FREE MOMENT.

C: $\angle$ TH. ORDER GUIDE FORCE.

Fig. 79 


\section{Conclusions. Further Developments}

Wave induced motions and loads

Although comparisons between tests and theoretical results generally have turned out favourably, further extension of theories and accumulation of data are necessary. There is still a lack of wave data, especially with regard to instrumental recordings. Also the strip theory calculations may be improved, for instance by including three-dimensional effects and by allowing for shallow water.

With regard to internal loads it has untill now to a great extent been necessary to introduce empirically obtained parameters and relations in the mathematical description of these variables. Further work in this field is needed in order to arrive at a complete theory for the calculation of impact pressures.

Wave induced vibrations have received much interest in recent years. We have until now mainly based our investigations on results from full-scale measurements. We are now continuing our efforts in this field by developing a theoretical model and an associated computer program.

We are presently also completing a computer program for calculation of motions and loads for semisubmersible drilling platforms. This program is coupled with SESAM-69 so as to produce internal stresses and deformations. Hence it becomes possible to run a loads and structural response analysis interactively.

In connection with the general coordination of wave loads and strength we are also developing a routine for relating the wave load prediction programs with our strength analysis programs. This is considered very important for the purpose of giving the designer a practical tool and relieving him of tedious data-handling.

\section{Structural analysis}

From the above tanker analysis one may conclude that transverse webs modelled as a plane membrane stiffened in its own plane may reflect the real behaviour of the membrane response, to an ac curacy of at least $10 \%$ in areas where buckling do not dominate the membrane response. Further accuracy, if desirable, should probably be sought through three-dimensional modelling of one-sided stiffeners and nonlinear treatment of initially imperfect plates.

We doubt at present the necessity for this accuracy in the model, because the bottle neck of accuracy today is the loads on the ship in an irregular sea. The above example certainly has proved that the superelement technique is a powerful, flexible and accurate tool for detail analysis of large and complex structures.

The technique has been applied to shell and solid problems, both within statics and dynamics with extremely good results. The development of the application programs within the superelement technique has gone on for three years, but has hardly reached its perfection, thus we are continuing further developments. There are no practical limits for using the SESAM-69 on even much larger problems than given by the previous example.

It is quite obvious that the coming years will bring real computer-aided structural design methods. These will be based on both automatic choice between several acceptable alternatives (optimization) and on the use of interactive, man-machine methods (time-shearing, on-line graphics). For the most immediate future it seems that just possibilities for accurate and simple evaluation of several alternatives is very valuable. These methods have to be based upon direct analysis and stress criteria. They may contain for instance optimum weight solutions for structural parts, but the choice of different arrangements etc., is best performed manually based upon the weights and other important parameters of the various alternatives. Complete, cost optimal solutions by means of automatic methods does not yet seem to be practical. 


\section{Machinery related stress analysis and design}

An important problem area in ship design, is the structural interaction between hull and bottom structures and machinery structures. There are numerous types of machinery difficulties which have been ascribed to hull deformations and interaction forces, as well as to machinery induced vibrations. In the examples which are presented, it is shown how valuable information may be obtained by using finite element methods, which also may be extended to vibration analysis. A further developrent will be to establish criteria for the design of bottom structures, and requirements to installation of shafting, transmission and machinery. Alternative principles of design which minimize interaction effects, should also be considered. Particularly the shafting system, including stern tube bearing and thrust bearing, lend itself to improvements in this respect.

\section{Propulsors}

Design control of propulsor should be made with emphasis on both optimum efficiency and minimization with regard to vibratory output. With main variables given by the hull wake and a conventional propulsion system, it is possible today to perform a "trial and error process" (interactive design) which at the design stage may reduce the vibratory level in operating ships below acceptable limits. More effort is required to be able to describe actual performance characteristics and excitation forces induced by un-conventional propulsors.

\section{References}

1) Pierson, J. W. and Moskowitz, L.: "A proposed spectral form for fully developed wind seas based on the similarity theory of S. A. Kitaigorodskii", Journ. of Geophysical Research, Vol. 69, No. 24, Dec. 1964.

2) Nordenstróm, N.: “Methods for predicting long term distributions of wave loads and probability of failure for ships. Appendix II. Relationships between visually estimated and theoretical wave heights and periods", Det norske Veritas, Research Department, Report No. 69-22-S.

3) Walden, H.: "Die Eigenschaften der Meereswellen im Nordatlantischen Ozean, Statistik 10jähriger Seebeobachtungen der Nordatlantischen Ozeanwetterschiffe", Deutscher Wetterdienst, Seewetteramt, Einzelveröffentlichungen Nr. 41, Hamburg 1964.

4) Nordenstr $\phi$ m, N.: "Appendix I. Long term distributions of wave height and period", Det norske Veritas, Research Department, Report No. 69-21-S.

5) Draper, L.: “Winter waves in the northern North sea at Famita station $57^{\circ} 30^{\prime} \mathrm{N}, 3^{\circ} 00^{\prime}$ E”, First International Conference on Port and Ocean Engineering under Arctic Conditions (POAC), Trondheim, August 1971.

6) Korvin-Kroukovsky, B. V. and Jacobs, W. R.: "Pitching and heaving motions of a ship in regular waves", Trans. SNAME, Vol. 65, 1957.

7) Grim, O.: “Die Schwingungen von Schwimmenden Zweidimensionalen Körpern”, Hamburg Schiffbau-Versuchsanst. Bericht Nr. 1171, 1959.

8) Fukuda, J.: "Computer program results for response operators of ship motions and vertical wave bending moments in regular waves", Kyushu University, Faculty of Engineering, Feb. 1966.

9) Salvesen, N., Tuck, E. O. and Faltinsen, O.: "Ship motions and sea loads", Det norske Veritas, Publication No. 75, March 1971.

10) Nordenstrọm, N., Faltinsen, O. and Pedersen, B.: "Prediction of wave-induced motions and loads for catamarans”, Det norske Veritas, Publication No. 77, Sept. 1971.

11) Vossers, G., Swaan, W. A. and Rijken, H.: "Vertical and lateral bending moment measurements on Series 60 models", International Shipbuilding Progress, Vol. 8, No. 83, 1961.

12) Wahab, R.: "Amidship forces and moments on a $C_{B}=0.80$ series 60 model in waves from various directions", Netherlands Ship Research Center TNO, Report No. 100 S, 1967.

13) Faltinsen, O.: "Comparison between theory and experiments of wave-induced loads for series 60 hull with $C_{B}=0.80$ ", Det norske Veritas, Research Department, Report No. 70-27-S.

14) Araldsen, P. O.: "The Application of the Superelement Method in Analysis and Design of Ship Structures and Machinery Components", Paper to be presented at the National Symposium on 
Computerized Structural Analysis and Design, George Washington University, Washington D.C., March 27-29, 1972.

15) Araldsen, P. O., Holtsmark, G. and Rọren, E. M. Q.: Analysis of oil tanker by SESAM-69. Seminar on the practical application of the finite element method, Trondheim, January 1971.

16) Germanischer Lloyd: Full scale tanker investigation “ESSO NORWAY”. Report Part A. Statical investigation. (Restricted Circulation).

17) Johnsen, I \& AL: Computer Program Information, CBC programs: Bulk Ships. Det norske Veritas, Report No. 68-37-S, Oslo 1968.

18) Staurset, I. A. \& AL: Computer Program Information, CBC programs: Oil Tankers. Det norske Veritas, Report No. 69-2-S, Oslo 1969.

19) Boberg, B. and Hagen, E.: "High strength steel in oil tankers and bulk/OBO carriers from a weight point of view", DnV information No. 6, Dec. 1970.

20) Haslum, K.: Users Manual NV 376, Torsional properties of thin walled sections. Det norske Veritas, Report No. 71-1-S, Oslo 1971.

21) Tónnesen, A.: Users Manual NV 377, Torsional response of non-prismatic beam. Det norske Veritas, Report No. 71-9-S, Oslo 1971.

22) Huse, E.: “Propeller Hull Vortex Cavitation”, Skipsmodelltanken, Publ. 106, 1971.

23) Yamazaki, R.: On the Theory of Unsteady Propeller Forces. Symp. on Naval Hydrodyn., 7th, Rome 1968. Wash., D.C., Office on Naval Research, 1968, p. 55.

24) Boes, C.: Der Propeller im instationären Geschwindigkeitsfeld. In. Shipb. Progr. 17 (1970): 189, pp. $159-173$.

25) Beveridge, J. L.: Analytical Prediction of Thrust Deduction for Submersibles and Surface Ships. J. Ship Res. 13 (1969): 4, pp. 258-271.

26) van Manen: "The NSMB vacuum towing tank", NSMB Information, 1971.

27) Edstrand, H.: “Kavitasjonslaboratoriet vid Statens Skeppsprovningsantalt”, SSPA Information, 1970.

28) Ræstad, E. A.: Estimation of a Marine Propeller's induced effects on the Hull Wake Field. $\mathrm{DnV}$, Report No. 72-3-M.

29) Schwanecke, H., Pylkkanen, J. and Andersson, G.: Ergebnisse der Strömungsmessungen im Propellerbereich F.S. "Meteor”. Deutsche Forschungsgemeinschaft. F 30/69. p. 135.

30) Vedeler, B.: Correlation of Propeller Induced Forces and Vibrations in Afterbody of a 220,000 t.dw. Tanker. Part II. Operation in Waves. DnV Report not yet available.

31) Nordenstr $\phi \mathrm{m}$, N., Faltinsen, O. and Pedersen, B.: "Prediction of wave-induced motions and loads for catamarans", DnV, Publication No. 77.

32) Sóntvedt, T.: “Propeller Induced Excitation Forces”, DnV, Publication No. 74.

33) Sóntvedt, T.: “The response of four marine propeller blades with different aspect ratio to given dynamic loading”, DnV, Report No. 72-4-M.

34) Holden, K. and Sontvedt, T.: "Propeller Cavitation as a Source to Vibration”, DnV, Report No. 72-5-M.

35) Holden, K.: "Type and extent of cavitation on hydrofoils and marine propeller blades", DnV, Report No. 72-2-M. 


\section{Summary of Discussions}

Mr. M. Maeda (Ishikawajima Harima Heavy Industries, Co., Ltd.) asked:

For the large tanker

\section{(1) Horizontal Main Structure}

In near future, structure of the large tanker is said to be changed from the vertical main type to the horizontal main type, because by applying limitation of the tank capacity (IMCO), the depth of the tank becomes to exceed the length of the tank and it is more reasonable to arrange the primary supporting member for longitudinal direction.

And by adopting this type, we can avoid to fit large cross ties of the vertical main, which is one of structures liable to occur some damages.

On the other hand, for the horizontal stringer, longitudinal stress will be added to conventional stress due to lateral load of liquid.

Therefore we must design the horizontal stringer by taking account of added stress.

However, as the horizontal main is reinforced by grillage, we can consider more reasonable comparing to the vertical main.

We would like to ask your opinions about some problems of horizontal main from point of view about structural strength.

\section{(2) Structure of primary supporting web}

Comparing structure of the primary supporting in our shipyards to that in European shipyards, we can point out difference about type of the bracket at end of the web.

In our shipyards, conventional type is to be stiffened by the continuous face plate, and in Europe the face plate of the web extends straightly beyond the end bracket, which is widely adopted for the large ship. (Fig. A-B)

We would like to ask about some damages at this area if you have, and what careful attention should be paid for, when we want to adopt this type for the large tanker.

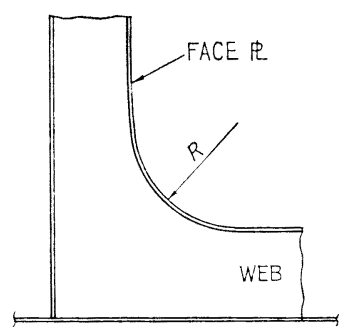

CONVENTIONAL TYPE

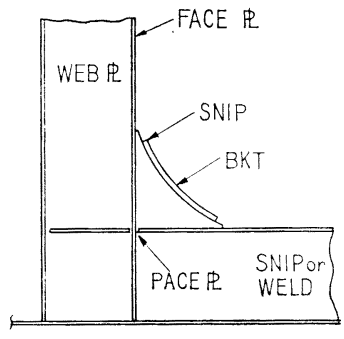

TYPE A

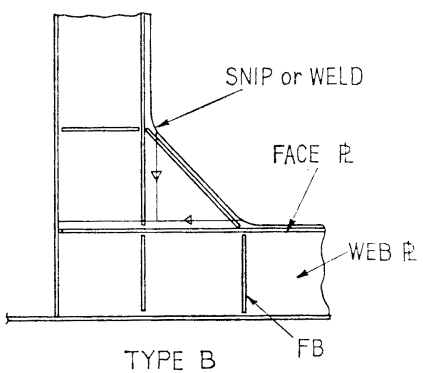

Mr. E. Abrahamsen replied:

\section{Horizontal Main Structure}

We agree in principle with the view that when the tank depth exceeds the tank length a horizontal main structure in the wing tank might be advantageous from a structural view point.

We feel that in such casses the tank structure design may develop in two alternative directions:

i) 1 or 2 large horizontal stringers around midheight of the tank, designed as platform decks with 
large openings to facilitate tank cleaning (the Kawasaki system). These stringers are, due to their position subjected to small longitudinal stresses, and may efficiently support transverse frame rings which in their turn carry the longitudinals. On the transverse bulkheads vertical webs carried by the stringers, and horizontal stiffeners will then be the natural system. Intermediate horizontal stringers and vertical stiffeners will be possible alternative. In the center tank bottom and deck one should possibly revert to the high centerline girder and reduce the transverses. For every large vessels a centerline bulkhead may be an alternative.

ii) 3 to 5 horizontal stringer rings in the wing tank, supporting a transverse stiffening system (transverse bottom frames, vertical side frames, transverse deck beams and vertical bulkhead stiffeners). In deck and bottom longitudinal side girders will be necessary. Also in the center tank longitudinal girders will have to be fitted at deck and bottom, and the transverse girders might be omitted.

This unorthodox design might have some merits for very large tankers where the heavy bottom and deck plating will have sufficient buckling strength with transverse stiffening. The ultimate strength of such a system should, however, be checked very carefully, also for the corroded sate before being accepted. Personally I would not favour this solution for the time being.

The upper and lower horizontal stringers will be subjected to longitudinal stresses of significant magnitude, and this should be taken into account when designing the stringers.

2. Structure of primary supporting web

See answer to Mr. Sakai.

3. Our rule requirements to double bottom scantlings and our standard double bottom calculation procedure are based on the loads from a homogeneously loaded hold filled to deck level. We do not take into account the rather uncertain form of the cargo as shown on your Fig. 1. On the other hand the stress level has been chosen somewhat on the safe side. It might also be possible that the internal friction in the cargo tends to equalize the pressure on the double bottom.

Mr. K. Hata (Nippon Kokan Co., Ltd.) asked:

1) Due to recent technological progress in the ship structure analysis method by using electric computer, it has become possible to obtain the considerably accurate responses of the structure against external forces.

However, the structure often remains indeterminate, because the load imposed on it by storm seas are as yet not accurately known.

Especially, depending upon the techniques of ship operation itself, there will be some possibilities to encounter with a critical load for the hull structure at rough sea condition.

On the other hand, the rule requirement of construction will be decided considering some external forces.

Therefore, we would like to hear your opinion on the operation of ship which will affect fairly upon the external forces.

2) There will be variance to some extent in the accuracy of workmanship and products during ship

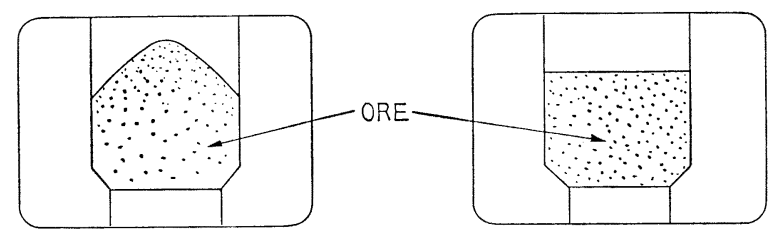

Fig. 1

Fig. 2 
construction, such as deformation, gap of fillet welding etc. and it will affect upon strength of ship structure.

Therefore, we would like to know how consideration of the above are paid in the Rule requirements.

3) The actual form of ore cargoes will generally be as shown on Fig. 1, which will have a different effect upon the local strength of double bottom comparing with the uniform loading of Fig. 2 .

We would like to hear your opinion on the above.

Mr. E. Abrahamsen replied:

1. As you may know we have at Det norske Veritas developed methods and a number of computer programs for calculating wave induced motions and loads. We have fair confidence in our predictions of external loads, as comparisons with measurements (model and full scale) have turned out favourably. In our calculations we also take speed reduction into account.

We consider speed to be the most important factor with regard to the influence which operation of the ship may have on the external forces. Change of course may have much the same effect as a speed reduction.

When calculating the effect of speed reduction, we use the probability of slamming and bow submergence as criteria for reducing speed.

Speed within the usual speed brackets for cargo ships do not seem to be very important with regard to bending moments and shear forces. Vertical acceleration, relative motion (i.e. external water pressure on side and deck) and slamming are, however, strongly dependent on speed.

When giving criteria for strength calculations based on a maximum speed the effect of speed reduction generally carried out by diligent masters should most definitely be taken into account for the above mentioned variables.

We would also like to mention that we are now working on a project aiming at establishing criteria for speed reduction in heavy weather that may be used as basis for designing a warning instrument in order to help the officers on the bridge in their decisions.

2. The rule requirements to the scantlings of the steel structures are based on a certain level of good workmanship, reference is made to Chapt. I, Sec. $6 \mathrm{C}$ of the Rule Book. It is the duty of our surveyors to check that the quality of the work is acceptable, and in his instructions certain standards have been given as guidance. These standards are very similar to the "Japanese Shipbuilding Quality Standard".

Mr. T. Sakai (Hitachi Shipbuilding \& Engineering Co., Ltd.) asked:

\section{Straight type bracket construction}

We hear that your society has accepted many ships with straight type bracket construction. As to this design some questions may have been asked at the time of another meeting such as Japanese Technical Committee of your society but here we wish to ask you following points.

(1) On what basis did you conclude this type is acceptable? From the results of fatigue test etc.? We think fatigue might be of problem.

(2) How about the results of annual inspection?

(3) We should like to take this opportunity to hear your opinion on the "fail safe design" of the hull? Judging from the results of fatigue test on straight type bracket model carried out in our country, study on the behaviour of crack propagation (e.g. life of the structure) becomes very 
important, we think.

2. Problem of large tanker over D.W. 400,000 tons

(1) What do you think would be of problem for the design and construction of ships over D.W. 400,000 tons?

(2) What do you think would be the optimum structural arrangement corresponding to ship's size and also in consideration of IMICO tank size limitation, for example number of longitudinal bulkheads corresponding to the ship's size or D.W., direction of primary supporting members, etc. ?

\section{Vibration}

Among the vibration problems you have experienced recently, is there any new problems which have not been considered or discussed so far?

Mr. E. Abrahamsen replied:

\section{Straight type bracket construction}

The straight type bracket construction has been applied on a number of ships classed with our Society since the fifties. Cracks reported during the years have been reasonably few in numbers and have mainly been caused by stress concentrations at the bracket ends. Brackets fractured have frequently been loaded in tension.

A finite element study of straight bracket design with alternative detail designs have shown that the stress concentration factor at the bracket ends may be kept within acceptable limits when:

a) Flange stiffening is kept not larger than necessary for stability requirements.

b) Small tapering angles of free edge stiffener.

c) Toe area is reasonable and gives good continuity.

On these conditions and with a maximum allowable tensile stress of $1500 \mathrm{kp} / \mathrm{cm}^{2}$ service experience has proved good and we accept straight bracket construction in ship structures on this basis.

Fatigue is obviously one of the reasons for cracks initiated in ship structures.

Specially in tankers with corrosive atmosphere and where increasing tank size has resulted in a relative increase in dynamic stress levels as compared with static stress levels.

Fatigue in straight bracket constructions is no more likely than in other details in the ship structure as long as the nominal allowable stresses based on static and dynamic loads are reasonable in relation to the stress concentration one must expect.

In approval today these facts are considered and different standard to the details for the many different designs of brackets may be accepted.

2. Results from annual inspections conclude the following

a) No cracks where nominal stress level in bracket is small.

b) No cracks in brackets frequently carrying compressive loads even at a high stress level.

c) Cracks occur when large tensile nominal stresses and rough workmanship at bracket ends.

Where fractures have occurred to the straight type brackets at the end of sniped edge stiffeners we have in some cases for repair connected the edge stiffener to the corresponding girder face bars. This seems to have proved successfull. As you will note this type of design is considered equal to the normal circular continuous face bar bracket as we accept similar nominal stress level.

3. An obvious advantage with the continuous face bar bracket design is that the discontinuities causing the most serious stress concentrations are eliminated. However, we have experienced that in some cases where an abrupt change in the face bar dimensions in the middle of the curved part 
have caused fatigue cracks in 'he buit weld between the two different face bars. In such cases there will exist immediate darig, ihat the fracture may propagate into the web plate and hence cause serious damage to the entire girder.

In the case of straight face bar bracket design the fractures developing at the end of the sniped edge stiffeners will not immediately propagate into the main girder as the fracture normally will stop at the face bar of the corresponding girder. 